\title{
Relative Prices of Food and the Volatility of Agricultural Commodities: Evidence for a Panel of Developing Economies
}

\author{
Carlos Martins-Filho and Maximo Torero
}

\subsection{Introduction}

Increases in relative prices of food items may have severe negative impact for consumer welfare. This can be particularly acute in low income countries where the share of household expenditure on food items is high. Recently, various time series on prices and returns for major agricultural commodities (rice, maize, soybeans, and wheat) have exhibited periods of increased price variability or high absolute values of returns. Whereas the negative link between high relative food prices and consumer welfare is empirically well documented in low income economies [see, e.g., conceptually (Deaton 1989), and for short-term effects (de Hoyos and Medved 2011; Ivanic and Martin 2008; Ivanic et al. 2012; Jacoby 2013; Wodon and Zaman 2010)], the potential link between high returns on major agricultural commodities and consumer welfare is, to our knowledge, poorly understood. Most of the existing work has focused on traditional measures of transmission of global price volatility to price volatility at the country level (see, e.g., Ceballos et al. 2015; Hernandez et al. 2014; Minot 2014; Zhao and Goodwin 2011). Moreover, the link between high absolute value of returns (volatility) of agricultural commodities at the global level and their impact on local prices of foodstuffs and consumer welfare has not been analyzed in the literature.

C. Martins-Filho $(\square)$

Department of Economics, University of Colorado, Boulder, CO 80309-0256, USA

IFPRI, 2033 K Street NW, Washington, DC 20006-1002, USA

e-mail: carlos.martins@colorado.edu; c.martins-filho@cgiar.org

M. Torero

IFPRI, 2033 K Street NW, Washington, DC 20006-1002, USA

e-mail:m.torero@cgiar.org 
Looking at volatility at the global level is important because although the food price spikes of 2008 and 2011 did not reach the heights of those during the 1970s, price volatility (measured in various ways) has arguably been at its highest level in the past 15 years (see Torero 2012). Wheat and maize prices have been particularly volatile. For soft wheat, for example, there were an average of 41 days of excessive price volatility per year between December 2001 and December 2006 (according to a measure of price volatility recently developed at IFPRI). ${ }^{1}$ From January 2007 to June 2011, the average number of days of excessive volatility was more than doubled to 88 per year (see Fig. 11.1).

High and volatile food prices are two different phenomena with distinct implications for consumers and producers. High food prices may harm poorer consumers because they need to spend more money on their food purchases and therefore may have to cut back on the quantity or quality of the food they buy. They may also be

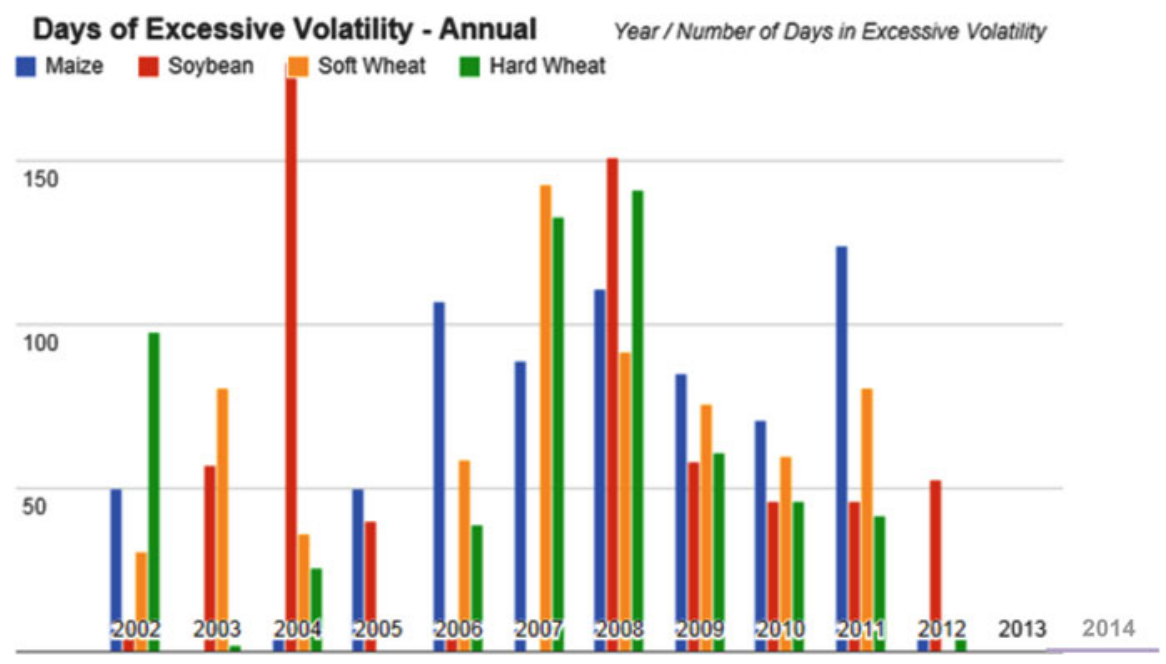

Fig. 11.1 Number of days with excessive volatility in commodity markets. Source: The number of days of excessive volatility is calculated using the Nonparametric Extreme Quantile (NEXQ) model for the dynamic evolution of daily returns based on historical data going back to 1954 . This model is then combined with extreme value theory to estimate higher-order quantiles of the return series, allowing for classification of any particular realized return (that is, effective return in the futures market) as extremely high or not. A period of time characterized by extreme price variation (volatility) is a period of time in which we observe a large number of extreme positive returns. An extreme positive return is defined to be a return that exceeds a certain pre-established threshold. This threshold is taken to be a high-order (95\%) conditional quantile, (i.e., a value of return that is exceeded with low probability: $5 \%$ ). One or two such returns do not necessarily indicate a period of excessive volatility. Periods of excessive volatility are identified based on a statistical test applied to the number of times the extreme value occurs in a window of consecutive 60 days. See Martins-Filho et al. (2015)

\footnotetext{
${ }^{1}$ See Martins-Filho et al. (2013, 2015).
} 
forced to economize on other needed goods and services. For food producers, higher food prices could raise their incomes - but only if they are net sellers of food-if increased global prices feed through to their local markets, and if the price changes on global markets do not also increase their production costs.

Apart from these effects of high food prices, price volatility also has significant effects on food producers and consumers. Greater price volatility can lead to increased losses for producers because it implies price changes that are larger and occur faster than what producers can adjust to. Uncertainty about prices makes it more difficult for farmers to make sound decisions about how and what to produce. For example, which crops should they produce? Should they invest in expensive fertilizers and pesticides? Should they purchase high-quality seeds? Without a realistic idea of how much they will earn from their products, farmers may become more pessimistic in their long-term planning and dampen their investments in areas that could otherwise improve their productivity. The positive relationship between price volatility and producers' expected losses can be modeled in a simple profit maximization model assuming producers are price takers. Still, it is important to mention that there is no uniform empirical evidence of the behavioral response of producers to volatility. By reducing supply, such a response could lead to higher prices, which in turn would hurt consumers.

It is important to remember that in rural areas the line between food consumers and producers is blurry. Many households both consume and produce agricultural commodities or foodstuffs. Therefore, if prices become more volatile and these households reduce their spending on seeds, fertilizer, and other inputs, this may affect the amount of food available for their own consumption. Even when the households are net sellers of food, producing less and having less to sell will reduce their household income and thus still impact their consumption decisions.

Finally, increased price volatility over time can also generate larger profits for investors, drawing new players into the market for agricultural commodities. Increased price volatility may thus lead to increased — and potentially speculativetrading that in turn can exacerbate price swings further, increasing volatility.

Despite the importance that price volatility may have for consumers, its impact on consumer welfare is notoriously difficult to measure due to income effects associated with price changes. In addition, the fact that in many low income countries economic agents are concomitantly consumers and producers of food creates added concerns and complications. Besides the inherent difficulties in adequately measuring consumer welfare, most empirical models for the dynamic evolution of returns for major agricultural commodities lack flexibility in modeling the conditional volatility (conditional standard deviation) of returns. Restrictive modeling of volatility can produce inconsistent return forecasts and inaccurate assessments and policy recommendations regarding the link between volatility and consumer welfare.

Since the empirical link between high relative food prices and consumer welfare is fairly well established, herein we propose an econometric/statistical model that attempts to model the relationship between conditional return volatility of major agricultural commodities and relative prices of food items/groups in a collection of 
low income countries. Our goal is to better understand the transmission of global volatility to local relative prices and therefore start to unveil its potential welfare effects.

\subsection{Methodology}

\subsubsection{Relative Food Prices at Country Level}

We are interested in understanding if, and how, changes in relative food prices (defined for certain groups of foodstuff) are related to volatility of agricultural commodities in global markets. To construct our variable of interest we use a Laspeyres price index for country $j=1, \ldots, J$ in time period $t=0, \ldots, T$. Let $N$ be the number of elements in a collection of goods and services that form a consumption basket and $p_{t j}=\left(p_{t j 1} \cdots p_{t j N}\right)^{\prime}$ be the corresponding vector of prices at time period $t$ in country $j$. We denote a representative consumption basket for this collection by the vector $q_{t j}=\left(q_{t j 1} \cdots q_{t j N}\right)^{\prime}$. The share of expenditures devoted to the $n$th element of the consumption basket at time $t$ in country $j$ is given by $s_{t j n}=p_{t j n} q_{t i n} /\left(p_{t j}^{\prime} q_{t j}\right)$, where $p_{t j}^{\prime} q_{t j}=\sum_{n=1}^{N} p_{t j n} q_{t j n}$. Similarly, for a set $I_{F}=\left\{i_{1}, \ldots, i_{F}\right\}$ that indexes $F$ elements from the representative basket, we define the share of expenditure on the food group $I_{F}$ by

$$
s_{t j, I_{F}}=\frac{p_{t j, I_{F}}^{\prime} q_{t j, I_{F}}}{p_{t j}^{\prime} q_{t j}}
$$

where $p_{t j, I_{F}}=\left(p_{t j i_{1}} \cdots p_{t j j_{F}}\right), q_{t j, I_{F}}=\left(q_{t j i_{1}} \cdots q_{t j I_{F}}\right)^{\prime}$ and $p_{t j, I_{F}}^{\prime} q_{t j, I_{F}}=$ $\sum_{n \in I_{F}} p_{t j n} q_{t j n}$. We note that $0 \leq s_{t j, I_{F}} \leq 1$. The Laspeyres price index for country $j$ from time period $t-1$ to time period $t$ can be written as

$$
L\left(p_{t j}, p_{t-1, j}, q_{t-1, j}\right)=\sum_{n=1}^{N} \frac{p_{t j n}}{p_{t-1, j n}} s_{t-1, j n} \text { for } t=1, \ldots, T,
$$

and the relative share of the Laspeyres price index associated with food group $I_{F}$ of the consumption basket is given by

$$
Y_{t j I_{F}}=\frac{\sum_{n \in I_{F}} \frac{p_{t j n}}{p_{t-1, j n}} s_{t-1, j n}}{L\left(p_{t j}, p_{t-1, j}, q_{t-1, j}\right)} \text { for } t=1, \ldots, T .
$$

Clearly, $Y_{t j I_{F}} \in(0,1)$ and represents the share of price index variations from time period $t-1$ to $t$ that correspond to the food group defined by the set $I_{F}$ in the consumption basket. If $Y_{t j I_{F}}$ is large, say in the vicinity of 1, the set $I_{F}$ in the consumption basket accounts for a large share of the price variability of the entire consumption basket $N$. In this case, most of the price changes in the consumption 
basket from time period $t-1$ to time period $t$ can be attributed to price variations on the elements in $I_{F}$.

If the consumption share in period $t-1$ of each element of the food group $I_{F}-$ $s_{t-1, j n}$-is fixed through time at $s_{0, j n}$ for all $n$ in $I_{F}$, then all changes in $Y_{t j I_{F}}$ can be attributed to changes in relative prices of food items that belong to $I_{F}$. Otherwise, the observed variability in $Y_{t j I_{F}}$ may result from both changes in relative prices and changes in expenditure shares. Throughout this paper, we will fix the share of goods and services through time at $s_{0, j n}$ and take $Y_{t j I_{F}}$ as our main variable of interest for defined sets of food groups $I_{F}$. In Sect. 11.3.1 we define the sets $I_{F}$ that we consider in our empirical model.

\subsubsection{Conditional Global Volatility and Its Relation to Country Level Relative Food Prices}

As mentioned above, we are interested in the impact that volatility of returns on agricultural commodities in global markets may have on $Y_{t j I_{F}}$. Hence, a key component of our empirical model is a measure of volatility. To obtain such a measure, we follow Martins-Filho et al. (2013) and envision the evolution of a commodity (rice, maize, soybeans, and wheat) price $P$ as a discretely indexed stochastic process $\left\{P_{t}\right\}_{t=0,1 \ldots}$. As such, the observation of a time series of commodity prices that extends from a certain time in the past up to the present time represents a realization of many possible collections of values that a stochastic process may take. We let the one-lag $\log$-returns associated with such time series be denoted by $r_{t}=\log \frac{P_{t}}{P_{t-1}}$ and assume that

$$
r_{t}=h^{1 / 2}\left(r_{t-1}, \ldots, r_{t-L}\right) \varepsilon_{t},
$$

where $h\left(r_{t-1}, \ldots, r_{t-L}\right)=h_{0}+\sum_{j=1}^{L} h_{j}\left(r_{t-j}\right), L \in \mathbb{N}$ represents the maximum lag on $r_{t}$ to be included as determinants of the conditional variance (squared volatility) of the process, $h_{j}$ are smooth non-negative functions that are otherwise unrestricted, $\varepsilon_{t} \sim \operatorname{IID}(0,1)$ and $E\left(h_{j}\left(r_{t-j}\right)\right)=0$ for all $j, h_{0}>0 .^{2}$

The model in (11.1) assumes that the dynamic evolution of log-returns for agricultural commodities can be described as a conditional location-scale model with conditional mean equal to zero and conditional volatility given by $\left(h_{0}+\sum_{j=1}^{L} h_{j}\left(r_{t-j}\right)\right)^{1 / 2}$, which is a function of $L$ lagged returns. Here, rather than assuming that volatility takes on a specific parametric structure, as in autoregressive conditional heteroscedastic (ARCH) or generalized autoregressive conditionally heteroscedastic (GARCH) models (Engle 1982; Bollerslev 1986), we flexibly model the impact of lag returns on volatility via the nonparametric functions $h_{j}$ as

\footnotetext{
${ }^{2}$ The requirement that $E\left(h_{j}\left(r_{t-j}\right)\right)=0$ for all $j$ is an identification condition for the conditional expectation $E\left(r_{t}^{2} \mid r_{t-1}, \ldots, r_{t-L}\right)=h_{0}+\sum_{j=1}^{L} h_{j}\left(r_{t-j}\right)$.
} 
in Fan and Yao (1998) and Martins-Filho et al. (2013). In this model, a measure of (conditional) volatility - a function of time - is obtained by estimating $h_{0}, h_{j}$ nonparametrically from a time series $\left\{r_{t}\right\}$.

A general stochastic model that relates $Y_{t j I_{F}}$ to the volatility of agricultural commodities can be expressed as

$$
E\left(Y_{t j I_{F}} \mid h^{1 / 2}\left(r_{t-1}, \ldots, r_{t-L}\right), W_{t}\right)=g^{-1}\left(m\left(h^{1 / 2}\left(r_{t-1}, \ldots, r_{t-L}\right), W_{t}\right)\right)
$$

for $t=L+1, \ldots, T$, where $W_{t} \in \mathbb{R}^{K}$ is a collection of suitably defined (exogenous) conditioning variables, $g$ is a strictly monotonic link function $g(x):(0,1) \rightarrow \mathbb{R}$, $m$ is a smooth function $m(x): \mathbb{R}^{K+1} \rightarrow \mathbb{R}$. Note that in (11.2) $g^{-1}$ takes values in $[0,1]$, which guarantees that the regression takes values in $(0,1)$, a constraint that must hold given that $Y_{t j I_{F}} \in(0,1)$. It would be desirable to impose as little structure as possible on the functional $m$ and the link $g$, however letting $m$ and $g$ be nonparametric functions creates difficulties both for estimation and for deriving practical empirical conclusions. As will be described shortly, we prefer a parametric specification that explicitly accounts for the fact that $Y_{t j I_{F}} \in(0,1)$, which has important implications for stochastic modeling.

\subsubsection{Beta Regression}

As described above, our variable of interest $-Y_{t j I_{F}}$ - takes values in $(0,1)$ and an appropriate parametric statistical model must reflect its range. A flexible univariate parametric (unconditional) density that accounts for such range is the beta density. The beta density associated with a random variable $Y$ is given by

$$
\pi(y ; p, q)=\frac{\Gamma(p+q)}{\Gamma(p) \Gamma(q)} y^{p-1}(1-y)^{q-1} \text { for } p, q>0,0<y<1 .
$$

If $\mu=\frac{p}{p+q}$ and $0<\phi=p+q$, then $0<E(Y)=\mu<1$ and $V(Y)=\frac{\mu(1-\mu)}{1+\phi}$. Here, we follow Ferrari and Cribari-Neto (2004) and consider a conditional beta density where $\mu(\cdot)$ is a function of a collection of conditioning variables $X_{t}^{\prime} \in \mathbb{R}^{K}$ with $K$ a natural number, such that for all $t$

$$
g\left(\mu_{t}\right)=\sum_{k=1}^{K} X_{t k} \theta_{k}=X_{t} \theta
$$

$\theta$ is a parameter vector taking values in a compact subset of $\mathbb{R}^{K}$ and $g\left(\mu_{t}\right)=$ $\log \frac{\mu_{t}}{1-\mu_{t}}$. This specific form for $g$ can be promptly recognized as the much used logit-link. 
It is easily verified that for a random sample $\left\{\left(Y_{t}, X_{t}\right)\right\}_{t=1}^{T}$, the log-likelihood function associated with the conditional beta model is given by $\ell(\theta, \phi)=$ $\sum_{t=1}^{T} \ell_{t}\left(\mu_{t}, \phi\right)$, where

$$
\begin{aligned}
\ell_{t}\left(\mu_{t}, \phi\right)= & \log \Gamma(\phi)-\log \Gamma\left(\mu_{t} \phi\right)-\log \Gamma\left(\left(1-\mu_{t}\right) \phi\right)+\left(\mu_{t} \phi-1\right) \log Y_{t} \\
& +\left(\left(1-\mu_{t}\right) \phi-1\right) \log \left(1-Y_{t}\right) .
\end{aligned}
$$

The score vectors associated with the parameters of the distribution are given by

$$
\begin{aligned}
\ell_{\theta}(\theta, \phi)= & \phi X^{\prime} D\left(Y^{*}-\mu^{*}\right), \\
\ell_{\phi}(\theta, \phi)= & \sum_{t=1}^{T}\left(\mu_{t}\left(Y_{t}^{*}-\mu_{t}^{*}\right)+\log \left(1-Y_{t}\right)-\psi\left(\left(1-\mu_{t}\right) \phi\right)\right. \\
& +\psi(\phi)),
\end{aligned}
$$

where $Y^{*}$ is a vector with $t$ th element given by $Y_{t}^{*}=\log \frac{Y_{t}}{1-Y_{t}}, \mu^{*}$ has $t$ th element $\mu_{t}^{*}=\log \frac{\mu_{t}}{1-\mu_{t}}, \psi(\cdot)$ is the digamma function, $D=\operatorname{diag}\left\{1 / g^{(1)}\left(\mu_{t}\right)\right\}_{t=1}^{T}$, and $X^{\prime}=$ $\left(X_{1}^{\prime} \cdots X_{T}^{\prime}\right)$, and $g^{(1)}(\cdot)$ denotes the first derivative of $g$. The values $\hat{\phi}$ and $\hat{\theta}$ that satisfy

$$
\ell_{\theta}(\hat{\theta}, \hat{\phi})=0 \text { and } \ell_{\phi}(\hat{\theta}, \hat{\phi})=0
$$

are the maximum likelihood estimators for $\theta$ and $\phi$. Ferrari and Cribari-Neto (2004) obtained the Fisher Information for this model, which is given by

$$
F(\theta, \phi)=\left(\begin{array}{ll}
F_{\theta \theta} & F_{\theta \phi} \\
F_{\phi \theta} & F_{\phi \phi}
\end{array}\right),
$$

where $F_{\theta \theta}=\phi X^{\prime} W X, F_{\theta \phi}=F_{\phi \theta}^{\prime}=\phi X^{\prime} D c, F_{\phi \phi}=\operatorname{trace}(D)$ with

$$
\begin{aligned}
& W=\operatorname{diag}\left\{\phi\left(\psi^{(1)}\left(\mu_{t} \phi\right)+\psi^{(1)}\left(\left(1-\mu_{t}\right) \phi\right)\right)\left(g^{(1)}\left(\mu_{t}\right)\right)^{-2}\right\}_{t=1}^{T}, \\
& D=\operatorname{diag}\left\{\psi^{(1)}\left(\mu_{t} \phi\right) \mu_{t}^{2}+\psi^{(1)}\left(\left(1-\mu_{t}\right) \phi\right)\left(1-\mu_{t}\right)^{2}-\psi^{(1)}(\phi)\right\}_{t=1}^{T}, \text { and } \\
& c=\left(c_{1}, \ldots, c_{T}\right)^{\prime}, \text { with } c_{t}=\phi\left(\psi^{(1)}\left(\mu_{t} \phi\right) \mu_{t}-\psi^{(1)}\left(\left(1-\mu_{t}\right) \phi\right)\left(1-\mu_{t}\right)\right) .
\end{aligned}
$$

Following standard arguments for obtaining the asymptotic distribution of maximum likelihood estimators (see Newey and McFadden 1994), we obtain for sufficiently large $T$ the following approximation

$$
\left(\begin{array}{l}
\hat{\theta} \\
\hat{\phi}
\end{array}\right)-\left(\begin{array}{l}
\theta \\
\phi
\end{array}\right) \sim N\left(0, F^{-1}(\theta, \phi)\right),
$$

which allows for asymptotically valid hypothesis testing on the parameters $\theta$ and $\phi$. 
It is desirable to obtain an expression for the first partial derivatives of $E\left(Y_{t} \mid X_{t}\right)$ with respect to the conditioning covariates $X_{t k}$. Given (11.3) and the logit-link, we have

$$
\frac{\partial}{\partial X_{t k}} E\left(Y_{t} \mid X_{t}\right)=\theta_{k} \frac{\exp \left(\sum_{k=1}^{K} X_{t k} \theta_{k}\right)}{1+\exp \left(\sum_{k=1}^{K} X_{t k} \theta_{k}\right)}
$$

\subsection{Data, Empirical Model, and Estimation}

\subsubsection{Data}

We have constructed a panel data set for nine Latin American countries: Costa Rica, El Salvador, Guatemala, Honduras, Ecuador, Peru, Mexico, Nicaragua and Panama, and one Asian country, India. Our variable of interest $-Y_{t j I_{F}}$ - was constructed for four food groups. They are: (i) Breads and cereals, (ii) meat, (iii) milk and other dairy products, and (iv) other foods. That is, there are four elements in $I_{F}$ and $I_{F}=$ $\{$ Breads and cereals, Meat, Milk and other dairy products, Otherfoods\}. These food groups were defined based on the international agricultural commodity groups rice, corn and wheat, and on standard grouping for food price indices, which is based on similarities in expenditure shares and market structure. $Y_{t j I_{F}}$ for (i)-(iv) were constructed using detailed data sets obtained from the national statistical institutes of each country. They included a price index of approximately 200 food and nonfood items that constitute a standard consumption basket, and their corresponding relative importance (weights) in the general consumption price index (CPI).

As components of $X_{t}$ in the previous section, we included a measure of the overall economic activity in the country given by a "Monthly index of economic activity." This is a Laspeyres index. It measures the evolution of economic activity, approximating the aggregated value of the industries included in the calculation of the gross domestic product (GDP). The index is given by $I_{t}=\sum_{i=1}^{n} I_{i t} w_{i 0}$ where $I_{t}$ is the general index in period $t ; I_{i t}$ is the index of industry $i$ (manufacturing, agricultural, etc.) in month $t ; w_{i 0}$ is the weight associated with industry $i$ in the calculation of GDP in the baseline period; $n$ is the number of industries; GDP is the aggregation of all the aggregated values of the productive activities. Activities included in the calculation of the IMAE (Indice Mensual de Actividad Economica-Monthly Index of Economic Activity) include: agricultural and livestock; mining; manufacturing; construction; water and electricity; trade; transport and communication; services for enterprises; services for financial intermediation; and hotel business. This variable was obtained from the Central Banks from each country. This index measures the total value of all different industries included in the calculation of the GDP. Additionally we included total imports, returns on oil prices, the monetary value (in US dollars) of liquid assets (M1) in circulation, and of course, our main conditioning 
variables of interest, the estimated volatility of international commodity prices (see the Appendix for a detailed list of sources for these variables in each country).

The volatility of returns for agricultural commodities was estimated using a sequence of returns based on prices for future contracts closest to maturity for: wheat CBOT (Chicago Board of Trade), wheat KCBT (Kansas City Board of Trade), corn, soybeans, and rice. From 01/28/1987 until 8/31/2009, daily data was taken from a historic file bought from the CME Group. From 09/01/2009 to 08/20/2013 daily data was obtained from daily updates, from CME and KCBT. The first observation for the time series estimation is for 01/03/1995.

\subsubsection{Empirical Model and Estimation}

Since $Y_{t j I_{F}} \in(0,1)$, we consider the following empirical specification for $g\left(\mu_{t}\right)$ in Sect. 11.2.3,

$$
g\left(\mu_{t}\right)=\theta_{0}+\sum_{l=1}^{4} W_{t l} \theta_{l}+\sum_{l=5}^{9} \theta_{l} h_{l}^{1 / 2}\left(r_{l, t-1}, r_{l, t-2}\right)
$$

where $h_{l}^{1 / 2}\left(r_{l, t-1}, r_{l, t-2}\right)$ must be estimated based on a time series of returns $\left\{r_{l t}\right\}$ on each of the five agricultural commodities given above, and $W_{t 1}, W_{t 2}, W_{t 3}$, and $W_{t 4}$ represent the monthly indicator of economic activity, total imports, M1 and return on oil prices, respectively. As in Sect. 11.2.3, we specify $g\left(\mu_{t}\right)=\log \frac{\mu_{t}}{1-\mu_{t}}$.

Each $h_{l}^{1 / 2}\left(r_{l, t-1}, r_{l, t-2}\right)$ is estimated nonparametrically by noting that from (11.1), we have for each $l$,

$$
E\left(r_{t l}^{2} \mid r_{l, t-1}, r_{l, t-2}\right)=h_{0}+h_{l 1}\left(r_{l, t-1}\right)+h_{l 2}\left(r_{l, t-2}\right) .
$$

Hence, for each $l$ we conduct a nonparametric additive regression estimation using the procedure discussed in Kim et al. (1999). The data we use on $r_{t l}$ has daily frequency, and all other data has monthly frequency. Thus, we aggregate our daily estimated conditional volatility to produce monthly estimates. We have experimented with the following measures of monthly volatility: (a) monthly means; (b) monthly medians; and (c) monthly inter-quartile ranges. There was little qualitative change in the results from using either of these measures. The results reported in Tables 11.1, 11.2, 11.3, 11.4, 11.5, 11.6, 11.7, 11.8, 11.9, 11.10, 11.11, 11.12, 11.13, $11.14,11.15,11.16,11.17,11.18,11.19$ and 11.20 in the Appendix are for monthly means. These estimates of (monthly) volatility, denoted by $\hat{h}_{l}^{1 / 2}\left(r_{l, t-1}, r_{l, t-2}\right)$, are then used as covariates for the maximum likelihood estimation of (11.7).

The maximum likelihood procedure requires the numerical solution of the homogeneous system of nonlinear equations given in (11.4). We use the Marquardt algorithm (see Marquardt 1963) to obtain a solution. The procedure requires initial values for the parameters $\phi$ and $\theta$, which we choose as suggested by Ferrari and 
Cribari-Neto (2004). ${ }^{3}$ Convergence of the algorithm is attained very quickly for all 40 (four food groups in ten countries) beta-regressions we have estimated. After obtaining $\hat{\theta}$ and $\hat{\phi}$ for all food groups and for all countries we estimated Fisher's information by $F(\hat{\theta}, \hat{\phi})$ using the expressions given in Sect. 11.2.3. $F(\hat{\theta}, \hat{\phi})$ is used to calculate the $z$-statistics reported in Tables 11.1, 11.2, 11.3, 11.4, 11.5, $11.6,11.7,11.8,11.9,11.10,11.11,11.12,11.13,11.14,11.15,11.16,11.17$, 11.18, 11.19 and 11.20 that appear in the Appendix. Also reported in these tables are the estimated marginal impact of the various covariates on the conditional expectation of $Y_{t j I_{F}}$. These are obtained using the estimates $\hat{\theta}$ to obtain estimated partial derivatives as given in (11.6).

\subsubsection{Discussion}

We first note that proportion of the variation on the general Laspeyres price index attributed to "Breads and Cereals," "Meats," and "Milk and other dairy products" is fairly small across all countries. These proportions vary from 0.02 to 0.10 for "Breads and Cereals," 0.02 to 0.09 for "Meats," and 0.03 to 0.06 for "Milk and other dairy products." As expected, the price variation of the catchall category "Other foods" is a much larger proportion of the variation on the general Laspeyres price index. It varies from proportion 0.05 to 0.26 .

For illustrative purposes, Figs. 11.2 and 11.3 provide Rosenblatt-kernel estimates of the density of the proportion of the general Laspeyres price index attributed to the food group "Bread and cereals" and "Meat" in Honduras and India. Figure 11.4 provides the Rosenblatt-kernel estimate of the density of the proportion of the general Laspeyres price index attributed to the food group "Milk and other dairy products" in Peru, and Fig. 11.5 provides the Rosenblatt-kernel estimate of the density of the proportion of the general Laspeyres price index attributed to the food group "Other foods" in Nicaragua. The estimated unimodal densities presented here are typical across the countries, but cases of bimodal densities do exist.

The results for all regressions are given in Tables 11.1, 11.2, 11.3, 11.4, 11.5, 11.6, 11.7, 11.8, 11.9, 11.10, 11.11, 11.12, 11.13, 11.14, 11.15, 11.16, 11.17, 11.18, 11.19 and 11.20 in the Appendix. The tables contain parameter estimates, $z$-statistics for the null hypothesis that $\theta_{k}=0$ against the alternative that $\theta_{k} \neq 0$ as well as the estimated marginal impact of each covariate evaluated at its average sample value. In addition, we provide pseudo- $R^{2}$ values for each regression. We can perceive some general regularities. For all food groups and for all countries, the precision parameter $\phi$ and the intercept $\theta_{0}$ are significant at the $5 \%$ level, with $\phi>0$ and $\theta_{0}<0$. Also, the pseudo- $R^{2}$ for the regressions are generally large, varying from 0.56 to 0.98 , indicating a reasonable overall fit for the models we have specified. ${ }^{4}$

\footnotetext{
${ }^{3}$ All codes for estimation were written using MATLAB and are available upon request.

${ }^{4}$ The exception is the regression for the Meat group in Costa Rica, where the pseudo- $R^{2}$ is 0.21 .
} 


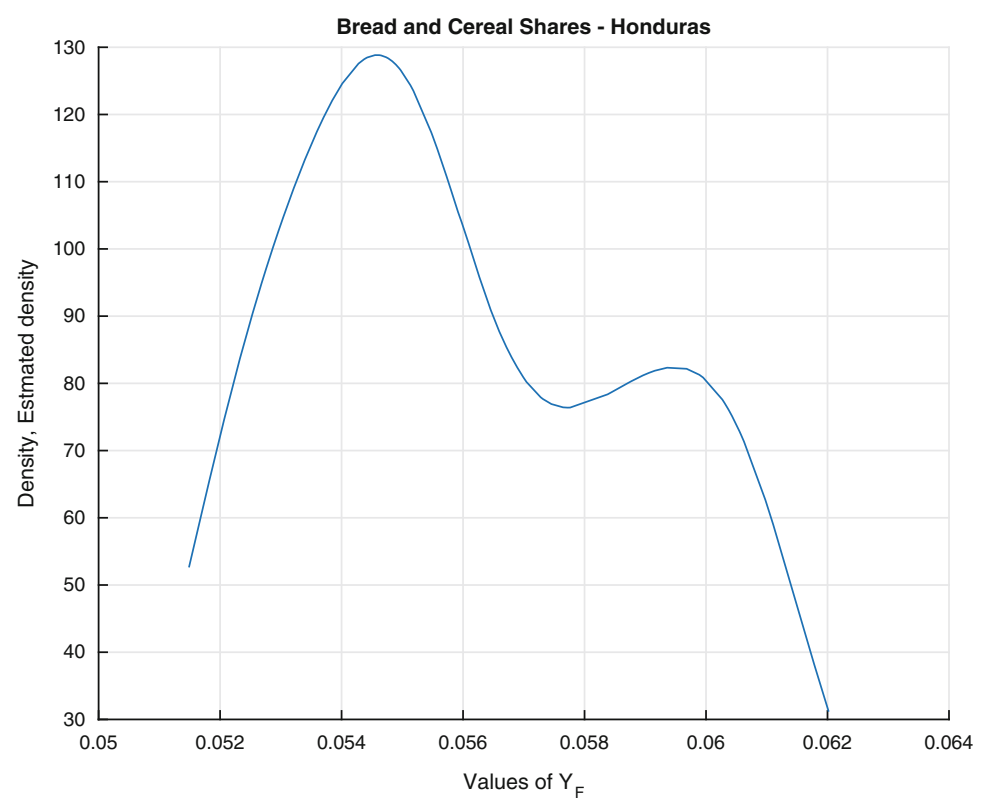

Fig. 11.2 Rosenblatt density estimate of the density of the proportion of general Laspeyres price index attributed to "Breads and cereals" in Honduras

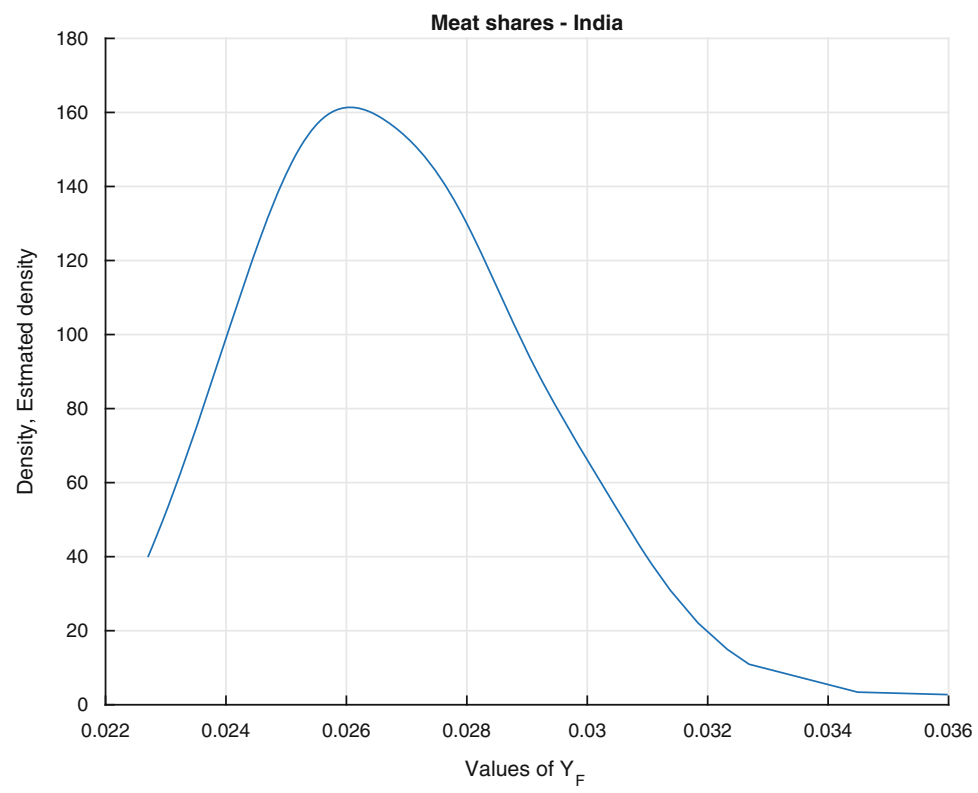

Fig. 11.3 Rosenblatt density estimate of the density of the proportion of general Laspeyres price index attributed to "Meat" in India 


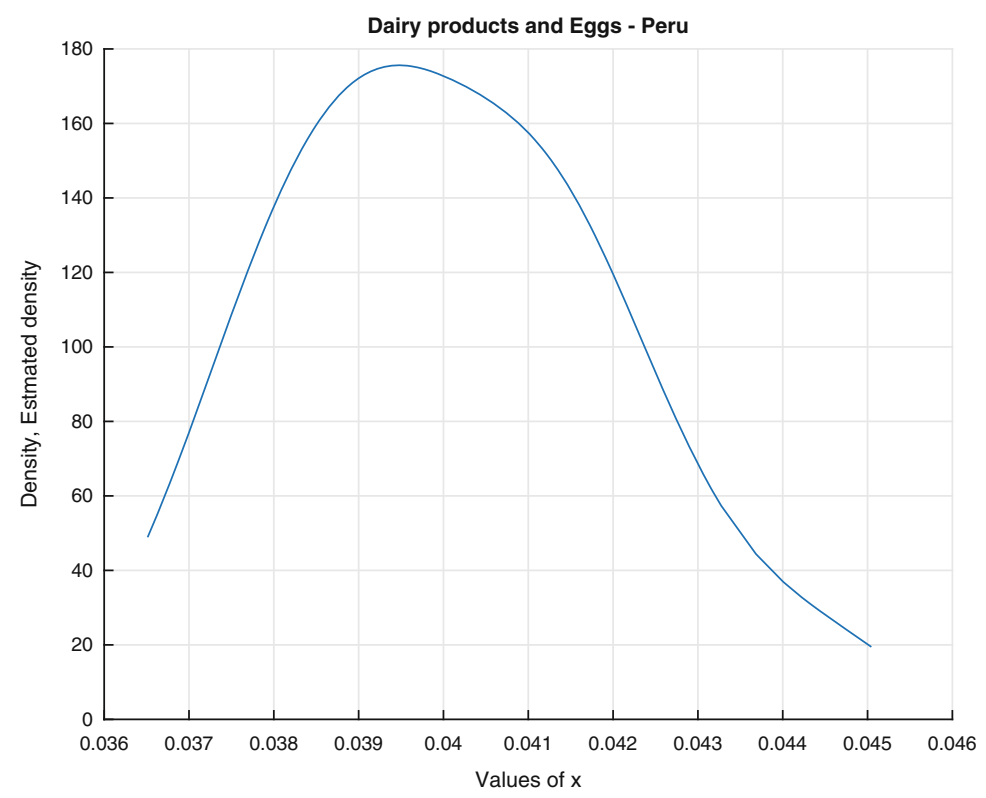

Fig. 11.4 Rosenblatt density estimate of the density of the proportion of general Laspeyres price index attributed to "Milk and dairy products" in Peru

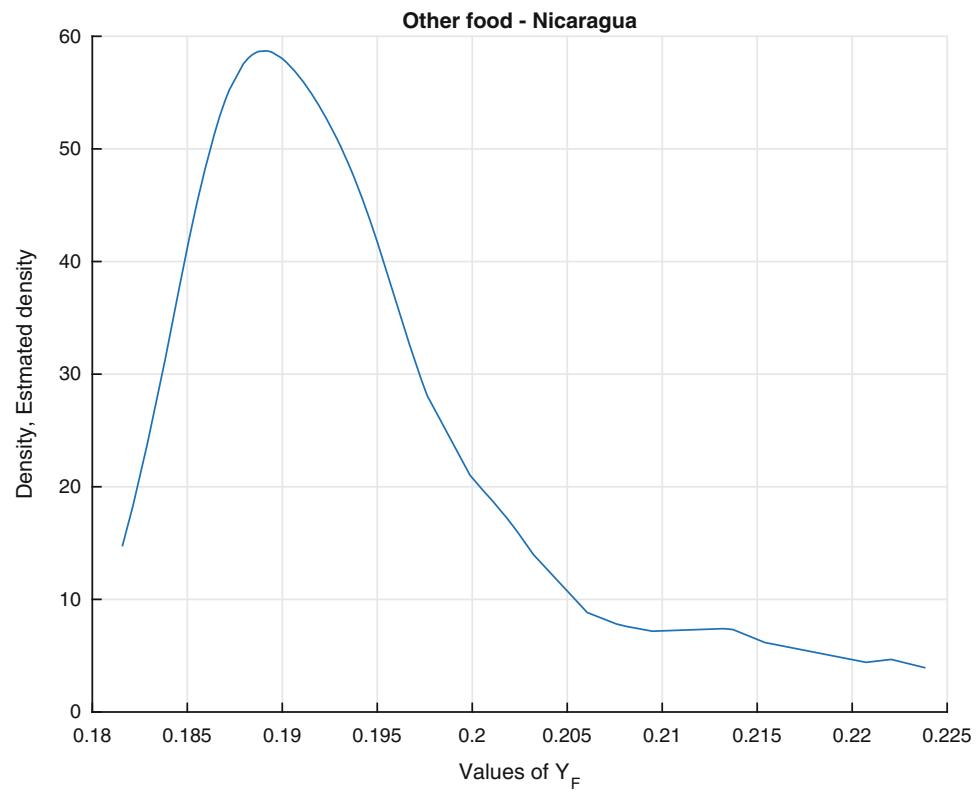

Fig. 11.5 Rosenblatt density estimate of the density of the proportion of general Laspeyres price index attributed to "Other foods" in Nicaragua 
In addition, for most regressions, plots of standardized residuals against the indices of the observations show no discernible pattern that may suggest misspecification. Figures 11.6 and 11.7 provide such plots for Honduras and India. The case of Honduras is quite typical, but the figure for India reveals that some observations may have significant leverage on the estimation. We chose to keep these observations in our calculations, but their removal normally boosts the estimated value of $\phi$.

For the food group "Breads and cereals" and for all countries, with the exception of El Salvador, Guatemala, and Nicaragua, the parameters associated with the volatility of wheat (either KCBT or CBOT) are positive and significant, mostly at the $5 \%$ level, and in Honduras and Mexico at the $10 \%$ level. ${ }^{5}$ Whenever the estimated parameter values associated with either of these volatilities is negative, it is insignificant at either the 5 or $10 \%$ level. Thus, there seems to be evidence that increased volatility of prices of wheat in global markets correlates with an increased proportion of the variation on the general Laspeyres price index that is attributed to the food group "Breads and cereals." Put differently, increased volatility on wheat markets may increase the relative prices of "Breads and cereals" in most countries. Accordingly, policies or market forces that mitigate volatility in these global markets

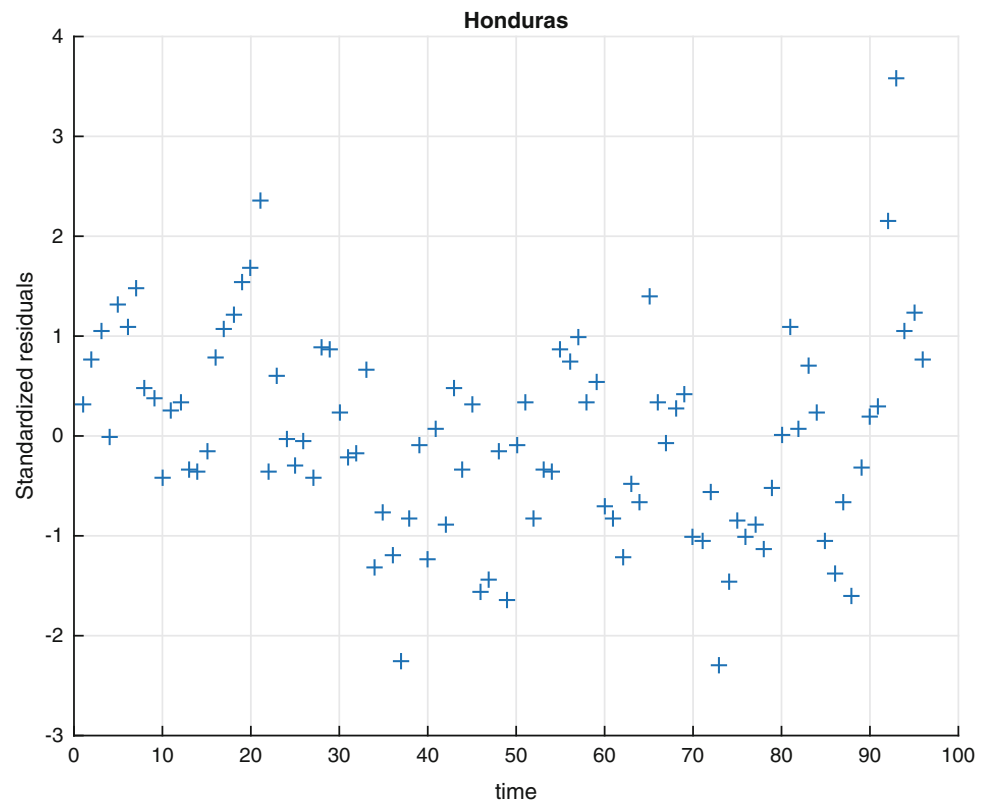

Fig. 11.6 Standardized residuals against the time index of the observations for "Other foods" for Honduras

\footnotetext{
${ }^{5}$ In El Salvador and Nicaragua the parameters associated with global wheat market volatility are statistically insignificant, and in Guatemala the parameter associated with the volatility of hard wheat (VolWCBOT) is negative and significant at the $10 \%$ level.
} 


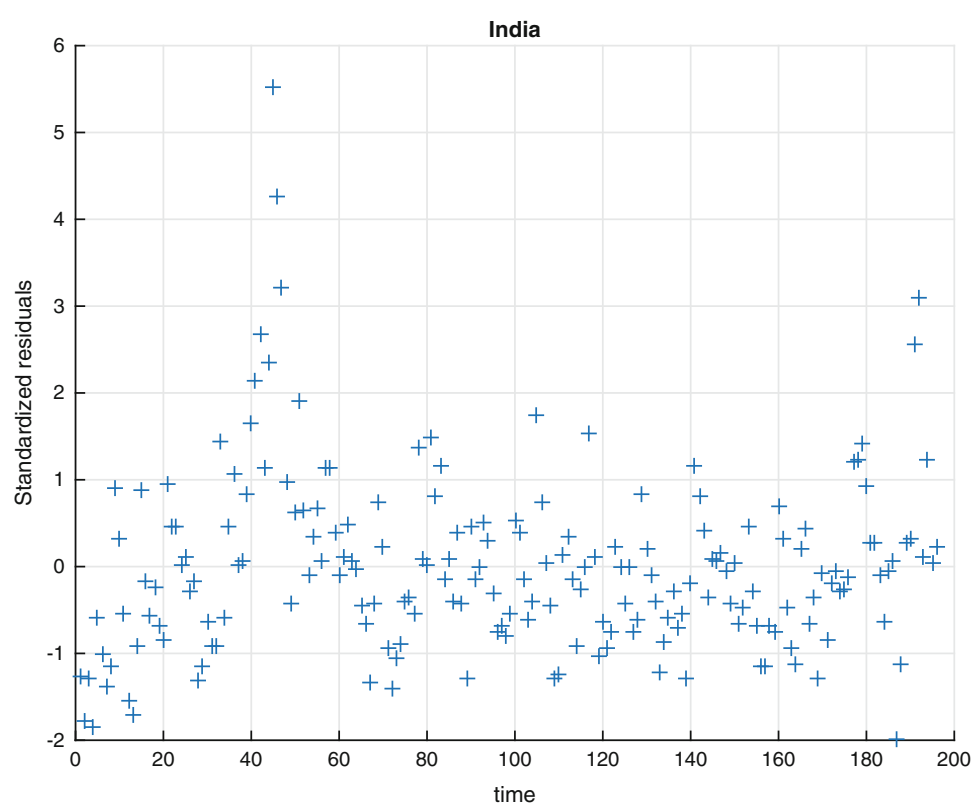

Fig. 11.7 Standardized residuals against the time index of the observations for "Other foods" for India

may help curb the share of general price movements that is attributable to "Breads and Cereals," therefore lessening the impact of changing prices on the budgets of households where this food group accounts for a larger share of expenditures.

The parameter associated with the index of economic activity is, whenever significant, negative for most food groups and countries (19 out of 24 cases). The exceptions are Costa Rica, El Salvador, and Guatemala where the parameter is positive and significant for the food groups "Breads and cereals," "Milk and other dairy products," and/or the catchall category "Other foods." Hence, there seems to be some evidence that increased economic activity dampens the proportion of the variation on the general Laspeyres price index that is attributed to most food groups. Thus, growth seems to lighten the impact of changing prices on the budgets of households where food accounts for a larger share of expenditures.

The parameter associated with the returns on oil prices is insignificant for virtually all food groups across all countries. The exceptions are "Breads and cereals" in India and "Meat" in Ecuador. The parameter associated with M1 is mostly positive and significant, or insignificant in most countries across all food groups. In addition, the absolute value of the estimated parameters associated with M1 is quite small, with values that are less than or equal to $10^{-4}$. Similarly, the estimated parameters associated with imports are also very small in absolute value. For this covariate, in most countries in Latin America, it has a statistically significant positive impact on the proportion of the variation on the general Laspeyres price 
index that is attributed to most food groups. In India the impact of this covariate is significant, but negative.

For the food group "Meats" and for most countries the parameter associated with the volatility of corn is positive and significant at either the 5 or $10 \%$ level. The exceptions are Costa Rica, where the parameter is negative and insignificant, and Nicaragua, Panama, and Peru where the parameters are always positive but not significant at the $10 \%$ level. Hence, there seems to be some evidence that increased volatility of prices of corn in global markets correlates with an increased proportion of the variation on the general Laspeyres price index that is attributed to the food group "Meats."

We note that the marginal impact of changes in covariates on $E\left(Y_{t j I_{F}} \mid \cdot\right)$ is relatively small across countries and food groups. This impact is rarely above 1 in absolute value, with exceptions for volatility of wheat in India and Costa Rica and volatility of rice in Peru for the "Other foods" group, volatility of rice in El Salvador and volatility of wheat, corn, and soy in Guatemala for the "Breads and cereals" group, and volatility of rice for the "Meat" group in Mexico. Thus, changes in volatility produce, at average values, changes on $E\left(Y_{t j I_{F}} \mid \cdot\right)$ of smaller magnitude.

\subsection{Conclusion}

The global food price crises of 2007/2008 and 2010/2011 led to economic difficulties for the poor, contributed to political turmoil in many countries, and in the long run could undermine confidence in global food markets, thereby hampering these markets' performance in balancing fundamental changes in supply, demand, and production costs. More important, food price crises can result in unreasonable or unwanted price fluctuations (volatility) that can harm the poor. Price volatility can have significant effects on food producers and consumers but the potential link between the volatility of returns for major agricultural commodities at the global level and welfare at the household level was not well understood. In this paper we took advantage of the fact that there is already important evidence on the effects of price levels on welfare and therefore focus on reducing the knowledge gap of the relationship between price volatility at the global level and relative prices of food items/groups in low income countries. Specifically, to close this gap we specify an empirical model that describes the dynamic evolution of the relative share of various food items in a Laspeyres price index as a function of the global volatility of returns for major agricultural commodities and a collection of observed covariates and relate it to the volatility of returns of agricultural commodities emerging from a fully nonparametric location-scale stochastic process as in Martins-Filho et al. (2015).

Our results show evidence for most countries of a relationship between relative prices and price volatility for the food group "Breads and cereals" with the volatility of wheat (either KCBT or CBOT). Thus, increased global volatility on wheat markets may increase the relative prices of "Breads and cereals" in most countries. 
Similarly, for the food group "Meats" for most countries the parameter associated with the volatility of corn is positive and significant being possibly the transmission mechanism for animal feed based on corn. Hence, and similarly to the case of wheat and breads and cereals, there also seems to be some evidence that increased volatility of prices of corn in global markets correlates with an increased proportion of the variation on the general Laspeyres price index that is attributed to the food group "Meats."

Accordingly, policies or market forces that mitigate volatility in these global markets may help curb the share of general price movements that is attributable to "Breads and cereals" and "Meat" at the country level lessening the impact of changing prices on the budgets of households where these food groups account for a larger share of expenditures. These results are of extreme relevance for the food price crises of 2007/2008 because volatility was, as initially mentioned, at its highest level during that period of time relative to the past 50 years. Even more the volatility was the highest for wheat and corn. For soft wheat there were an average of 41 days of excessive price volatility per year between December 2001 and December 2006 while from January 2007 to June 2011, the average number of days of excessive volatility more than doubled to 88 per year.

The question is then what countries can do to cope with excessive volatility. In this light, many countries try to stabilize prices through trade policies and management of food reserves. With respect to reserves, international experience in the management and use of so-called strategic grain reserves is mixed, with frequent concerns about operational inefficiencies, financial costs, and disincentives for private traders to perform normal arbitrage functions. Some of the problems with grain reserves can be overcome by establishing clear and open rules for market interventions, including the private sector in the tendering for supplies for the reserves, combining grain and financial reserves to reduce costs. However, instead of domestic buffer stocks, some authors posit the advantages of holding reserves at the international level or regional level. Among other reasons, this type of intervention can reduce storage costs and, if managed by an international intelligence unit, can reduce governments' political management of the resources. Albeit compelling, an international or regional reserve poses other important obstacles. Politically, it requires multinational coordination and sound governance. Economically, it might disincentive private grain storage. Operationally, it is important to establish clear triggers for market intervention. Similarly, there is important evidence showing that using trade policies to reduce price volatility is not effective and on the contrary could have important welfare costs as shown by Martin and Anderson (2011) and Anderson and Nelgen (2012).

On the other hand, there is evidence that improved transport infrastructure helps reduce price variability. Roads are useful means to spread out regional shocks; if a certain region is hit by a shock (weather or other), it can import food from another region. For example, during the food crisis of 2007/2008, it is shown that regions with better infrastructure in Indonesia were not hit as hard as those poorly connected. In this line, the World Bank (2010) argues that after controlling for exchange rates and world prices, remote provinces appear to have higher 
levels of price volatility than well-connected provinces. It confirms the importance of investment in infrastructure. In particular, it demonstrates that the constraints created by geography and remoteness to the transmission of price signals can be alleviated by improving the quality of infrastructure. This result is consistent with the fact that in our analysis we also find some evidence that increased economic activity dampens the proportion of the variation on the general Laspeyres price index that is attributed to most food groups. Thus, growth seems to lighten the impact of changing prices on the budgets of households where food accounts for a larger share of expenditures.

In summary, price volatility is likely to remain an important challenge in the medium and long run and, as was shown, a link exists between the volatility of returns for major agricultural commodities and relative prices of certain food groups. It is in this sense that further research is needed to understand alternative policies at the global, regional, and local level that could help countries to cope with excessive volatility.

\section{Appendix}

\section{Tables}

Table 11.1 Model: $Y_{t I_{F}}$-India, $n=196$

\begin{tabular}{l|l|r|l|l|r|l}
\hline & \multicolumn{3}{|l}{ Breads and cereals } & \multicolumn{2}{l}{ Meat } \\
\cline { 2 - 7 } Parameter & Estimate & $z$-statistic & $\begin{array}{l}\text { Marginal } \\
\text { impact }\end{array}$ & Estimate & $z$-statistic & $\begin{array}{l}\text { Marginal } \\
\text { impact }\end{array}$ \\
\hline$\phi$ & 8322.0225 & 9.8975 & & 8052.0188 & 9.8966 & \\
\hline$\theta_{0}$ (Intercept $)$ & -3.3859 & -45.8605 & -0.1181 & -3.4186 & -40.4528 & -0.0918 \\
\hline$\theta_{1}($ EconAct $)$ & -0.0001 & -0.4041 & 0 & -0.0012 & -2.9929 & 0 \\
\hline$\theta_{2}$ Imports $)$ & 0 & -4.1538 & 0 & 0 & -3.8414 & 0 \\
\hline$\theta_{3}($ M1 $)$ & 0 & 0.8828 & 0 & 0 & 5.1483 & 0 \\
\hline$\theta_{4}($ Return on Oil $)$ & 0.1347 & 2.5937 & 0.0047 & 0.0363 & 0.6084 & 0.001 \\
\hline$\theta_{5}($ VolCorn $)$ & 3.7597 & 1.6468 & 0.1311 & 4.8465 & 1.8106 & 0.1302 \\
\hline$\theta_{6}($ VolSoy $)$ & -7.9867 & -2.9294 & -0.2785 & -11.1097 & -3.5301 & -0.2985 \\
\hline$\theta_{7}($ VolRice $)$ & -8.0383 & -3.8538 & -0.2803 & -12.6843 & -5.209 & -0.3408 \\
\hline$\theta_{8}($ VolWCBOT $)$ & 24.7865 & 3.972 & 0.8644 & 11.699 & 1.6275 & 0.3143 \\
\hline$\theta_{9}($ VolWKCBT $)$ & -7.448 & -1.3926 & -0.2597 & -2.8586 & -0.4622 & -0.0768 \\
\hline Pseudo- $R^{2}$ & 0.61 & & & & 0.63 & \\
\hline
\end{tabular}


Table 11.2 Model: $Y_{t I_{F}}$-India, $n=196$

\begin{tabular}{|c|c|c|c|c|c|c|}
\hline \multirow[b]{2}{*}{ Parameter } & \multicolumn{3}{|c|}{ Milk and other dairy products } & \multicolumn{3}{|l|}{ Other foods } \\
\hline & Estimate & $z$-statistic & $\begin{array}{l}\text { Marginal } \\
\text { impact }\end{array}$ & Estimate & $z$-statistic & $\begin{array}{l}\text { Marginal } \\
\text { impact }\end{array}$ \\
\hline$\phi$ & $18,235.638$ & 9.8986 & & 2959.3164 & 9.8965 & \\
\hline$\theta_{0}($ Intercept $)$ & -3.3944 & -67.3571 & -0.115 & -2.8103 & -27.592 & -0.1442 \\
\hline$\theta_{1}($ EconAct $)$ & -0.0006 & -2.5677 & 0 & -0.0012 & -2.374 & -0.0001 \\
\hline$\theta_{2}$ (Imports) & 0 & -6.9294 & 0 & 0 & -1.9511 & 0 \\
\hline$\theta_{3}(\mathrm{M} 1)$ & 0 & 5.2652 & 0 & 0 & 2.9808 & 0 \\
\hline$\theta_{4}($ Return on Oil $)$ & 0.0456 & 1.2867 & 0.0015 & -0.1576 & -2.1992 & -0.0081 \\
\hline$\theta_{5}($ VolCorn $)$ & 0.9446 & 0.5976 & 0.032 & 2.2964 & 0.7103 & 0.1178 \\
\hline$\theta_{6}$ (VolSoy) & -6.1414 & -3.3173 & -0.2081 & -8.4597 & -2.2293 & -0.434 \\
\hline$\theta_{7}($ VolRice $)$ & -0.9646 & -0.6754 & -0.0327 & -12.9179 & -4.4025 & -0.6627 \\
\hline$\theta_{8}($ VolWCBOT $)$ & 7.9036 & 1.8516 & 0.2678 & 20.5499 & 2.3618 & 1.0542 \\
\hline$\theta_{9}($ VolWKCBT) & 2.1534 & 0.5863 & 0.073 & -5.2261 & -0.6984 & -0.2681 \\
\hline Pseudo- $R^{2}$ & 0.58 & & & & 0.58 & \\
\hline
\end{tabular}

Table 11.3 Model: $Y_{t I_{F}}-$ Costa Rica, $n=161$

\begin{tabular}{l|l|r|l|l|r|l}
\hline & \multicolumn{3}{l|}{ Breads and cereals } & \multicolumn{2}{l}{ Meat } \\
\cline { 2 - 8 } Parameter & Estimate & $z$-statistic & $\begin{array}{l}\text { Marginal } \\
\text { impact }\end{array}$ & Estimate & $z$-statistic & $\begin{array}{l}\text { Marginal } \\
\text { impact }\end{array}$ \\
\hline$\phi$ & $26,075.522$ & 8.9718 & & $45,212.82$ & 8.9719 & \\
\hline$\theta_{0}($ Intercept $)$ & -3.6305 & -98.3296 & -0.1566 & -3.173 & -106.2465 & -0.1228 \\
\hline$\theta_{1}($ EconAct $)$ & 0.0004 & 1.8016 & 0 & -0.0001 & -0.7093 & 0 \\
\hline$\theta_{2}($ Imports $)$ & -0.0001 & -2.1393 & 0 & 0 & 2.0016 & 0 \\
\hline$\theta_{3}($ M1 $)$ & 0 & 4.0094 & 0 & 0 & -0.2263 & 0 \\
\hline$\theta_{4}($ Return on Oil $)$ & -0.0237 & -0.8253 & -0.001 & -0.0045 & -0.195 & -0.0002 \\
\hline$\theta_{5}($ VolCorn $)$ & -3.0216 & -1.7949 & -0.1304 & -0.1286 & -0.0974 & -0.005 \\
\hline$\theta_{6}($ VolSoy $)$ & 9.0852 & 6.4816 & 0.392 & 0.2527 & 0.2246 & 0.0098 \\
\hline$\theta_{7}($ VolRice $)$ & 2.3734 & 1.636 & 0.1024 & -0.4263 & -0.3762 & -0.0165 \\
\hline$\theta_{8}($ VolWCBOT $)$ & 7.5157 & 2.0229 & 0.3243 & -3.4331 & -1.1423 & -0.1329 \\
\hline$\theta_{9}($ VolWKCBT $)$ & 8.689 & 2.2975 & 0.3749 & 1.4881 & 0.4892 & 0.0576 \\
\hline Pseudo- $R^{2}$ & 0.94 & & & & 0.21 & \\
\hline
\end{tabular}


Table 11.4 Model: $Y_{t I_{F}}$ - Costa Rica, $n=161$

\begin{tabular}{|c|c|c|c|c|c|c|}
\hline \multirow[b]{2}{*}{ Parameter } & \multicolumn{3}{|c|}{ Milk and other dairy products } & \multicolumn{3}{|l|}{ Other foods } \\
\hline & Estimate & $z$-statistic & $\begin{array}{l}\text { Marginal } \\
\text { impact }\end{array}$ & Estimate & $z$-statistic & $\begin{array}{l}\text { Marginal } \\
\text { impact }\end{array}$ \\
\hline$\phi$ & 6196.3183 & 8.9698 & & $10,060.627$ & 8.9724 & \\
\hline$\theta_{0}($ Intercept $)$ & -4.6539 & -56.4141 & -0.168 & -2.1065 & -64.0618 & -0.3418 \\
\hline$\theta_{1}($ EconAct $)$ & 0.0034 & 6.6053 & 0.0001 & 0.0009 & 4.6255 & 0.0002 \\
\hline$\theta_{2}$ (Imports) & -0.0001 & -1.7584 & 0 & -0.0001 & -3.7474 & 0 \\
\hline$\theta_{3}(\mathrm{M} 1)$ & 0 & 0.1881 & 0 & 0 & 4.0935 & 0 \\
\hline$\theta_{4}($ Return on Oil $)$ & -0.0455 & -0.7101 & -0.0016 & -0.0074 & -0.2882 & -0.0012 \\
\hline$\theta_{5}($ VolCorn $)$ & 3.3943 & 0.884 & 0.1225 & 3.4899 & 2.3559 & 0.5663 \\
\hline$\theta_{6}($ VolSoy $)$ & 8.2956 & 2.633 & 0.2994 & -0.0698 & -0.0557 & -0.0113 \\
\hline$\theta_{7}$ (VolRice) & 9.0529 & 2.7014 & 0.3268 & 2.2767 & 1.7793 & 0.3694 \\
\hline$\theta_{8}($ VolWCBOT $)$ & 6.7551 & 0.8206 & 0.2438 & 3.2624 & 0.9848 & 0.5294 \\
\hline$\theta_{9}($ VolWKCBT $)$ & 15.4374 & 1.8353 & 0.5572 & 6.8953 & 2.0505 & 1.1189 \\
\hline Pseudo- $R^{2}$ & 0.93 & & & & 0.94 & \\
\hline
\end{tabular}

Table 11.5 Model: $Y_{t I_{F}}$-Ecuador, $n=101$

\begin{tabular}{l|l|r|l|l|r|l}
\hline & \multicolumn{3}{l}{ Breads and cereals } & \multicolumn{2}{l}{ Meat } \\
\cline { 2 - 8 } Parameter & Estimate & $z$-statistic & $\begin{array}{l}\text { Marginal } \\
\text { impact }\end{array}$ & Estimate & $z$-statistic & $\begin{array}{l}\text { Marginal } \\
\text { impact }\end{array}$ \\
\hline$\phi$ & $17,823.992$ & 7.105 & & $17,059.821$ & 7.1061 & \\
\hline$\theta_{0}$ (Intercept $)$ & -4.4994 & -40.662 & -0.0942 & -3.0999 & -46.642 & -0.1984 \\
\hline$\theta_{1}($ EconAct $)$ & 0.0003 & 1.3192 & 0 & -0.0003 & -2.5424 & 0 \\
\hline$\theta_{2}($ Imports $)$ & 0 & -0.0158 & 0 & 0 & -0.2144 & 0 \\
\hline$\theta_{3}($ M1 $)$ & 0 & 0.9764 & 0 & 0 & 3.264 & 0 \\
\hline$\theta_{4}($ Return on Oil $)$ & 0.0387 & 0.6157 & 0.0008 & 0.0665 & 1.7533 & 0.0043 \\
\hline$\theta_{5}($ VolCorn $)$ & -5.7378 & -1.1672 & -0.1201 & 9.0724 & 3.0926 & 0.5807 \\
\hline$\theta_{6}($ VolSoy $)$ & 15.704 & 4.1448 & 0.3288 & -3.8565 & -1.6903 & -0.2468 \\
\hline$\theta_{7}($ VolRice $)$ & 5.1702 & 0.8926 & 0.1083 & 11.269 & 3.2368 & 0.7212 \\
\hline$\theta_{8}($ VolWCBOT $)$ & -5.5333 & -0.6799 & -0.1159 & 3.5782 & 0.7259 & 0.229 \\
\hline$\theta_{9}($ VolWKCBT $)$ & 20.9795 & 2.5906 & 0.4393 & 3.5107 & 0.7179 & 0.2247 \\
\hline Pseudo- $R^{2}$ & 0.83 & & & & 0.86 & \\
\hline
\end{tabular}


Table 11.6 Model: $Y_{t I_{F}}$-Ecuador, $n=101$

\begin{tabular}{l|l|r|l|l|r|l}
\hline & \multicolumn{2}{l}{ Milk and other dairy products } & \multicolumn{2}{l}{ Other foods } \\
\cline { 2 - 8 } Parameter & Estimate & $z$-statistic & $\begin{array}{l}\text { Marginal } \\
\text { impact }\end{array}$ & Estimate & $z$-statistic & $\begin{array}{l}\text { Marginal } \\
\text { impact }\end{array}$ \\
\hline$\phi$ & $91,687.291$ & 7.1062 & & $15,227.761$ & 7.1065 & \\
\hline$\theta_{0}$ (Intercept $)$ & -3.2196 & -94.4869 & -0.1429 & -1.6972 & -39.1194 & -0.3331 \\
\hline$\theta_{1}($ EconAct $)$ & 0 & -0.6612 & 0 & -0.0001 & -1.4768 & 0 \\
\hline$\theta_{2}($ Imports $)$ & 0 & 4.1872 & 0 & 0 & 2.2185 & 0 \\
\hline$\theta_{3}($ M1 $)$ & 0 & 0.0493 & 0 & 0 & 8.2742 & 0 \\
\hline$\theta_{4}($ Return on Oil $)$ & 0.0004 & 0.0218 & 0 & 0.0034 & 0.1382 & 0.0007 \\
\hline$\theta_{5}($ VolCorn $)$ & -1.4647 & -0.9732 & -0.065 & -4.4661 & -2.3233 & -0.8767 \\
\hline$\theta_{6}($ VolSoy $)$ & 0.0609 & 0.052 & 0.0027 & 2.9095 & 1.9523 & 0.5711 \\
\hline$\theta_{7}($ VolRice $)$ & 2.8649 & 1.6069 & 0.1272 & 6.1867 & 2.7241 & 1.2144 \\
\hline$\theta_{8}($ VolWCBOT $)$ & 0.1769 & 0.0699 & 0.0079 & 1.1011 & 0.3418 & 0.2161 \\
\hline$\theta_{9}($ VolWKCBT $)$ & 4.0488 & 1.6159 & 0.1797 & 1.2828 & 0.4018 & 0.2518 \\
\hline Pseudo- $R^{2}$ & 0.85 & & & & 0.96 & \\
\hline & & & & & & \\
\hline
\end{tabular}

Table 11.7 Model: $Y_{t I_{F}}-$ El Salvador, $n=158$

\begin{tabular}{|c|c|c|c|c|c|c|}
\hline \multirow[b]{2}{*}{ Parameter } & \multicolumn{3}{|c|}{ Breads and cereals } & \multicolumn{3}{|l|}{ Meat } \\
\hline & Estimate & $z$-statistic & $\begin{array}{l}\text { Marginal } \\
\text { impact }\end{array}$ & Estimate & $z$-statistic & $\begin{array}{l}\text { Marginal } \\
\text { impact }\end{array}$ \\
\hline$\phi$ & 5561.2261 & 8.888 & & $12,950.628$ & 8.8873 & \\
\hline$\theta_{0}($ Intercept $)$ & -2.1186 & -28.6153 & -0.1978 & -2.5586 & -36.4601 & -0.1052 \\
\hline$\theta_{1}($ EconAct $)$ & -0.0015 & -3.8894 & -0.0001 & -0.0011 & -2.9273 & 0 \\
\hline$\theta_{2}$ (Imports) & 0 & 0.6865 & 0 & -0.0001 & -1.9564 & 0 \\
\hline$\theta_{3}(\mathrm{M} 1)$ & 0.0001 & 1.6496 & 0 & 0 & -0.5514 & 0 \\
\hline$\theta_{4}($ Return on Oil $)$ & 0.0263 & 0.5228 & 0.0025 & 0.0079 & 0.1643 & 0.0003 \\
\hline$\theta_{5}($ VolCorn $)$ & 3.5452 & 1.8955 & 0.331 & 5.0484 & 2.819 & 0.2075 \\
\hline$\theta_{6}($ VolSoy $)$ & 4.9424 & 2.0159 & 0.4614 & -13.2289 & -5.384 & -0.5438 \\
\hline$\theta_{7}$ (VolRice) & -11.1869 & -6.2487 & -1.0444 & -6.4993 & -3.7905 & -0.2672 \\
\hline$\theta_{8}($ VolWCBOT $)$ & 2.2313 & 0.37 & 0.2083 & -11.5973 & -2.0402 & -0.4767 \\
\hline$\theta_{9}($ VolWKCBT $)$ & 2.9245 & 0.6448 & 0.273 & 5.62 & 1.3124 & 0.231 \\
\hline Pseudo- $R^{2}$ & 0.56 & & & & 0.85 & \\
\hline
\end{tabular}


Table 11.8 Model: $Y_{t I_{F}}-\mathrm{El}$ Salvador, $n=158$

\begin{tabular}{|c|c|c|c|c|c|c|}
\hline \multirow[b]{2}{*}{ Parameter } & \multicolumn{3}{|c|}{ Milk and other dairy products } & \multicolumn{3}{|c|}{ Other foods } \\
\hline & Estimate & $z$-statistic & $\begin{array}{l}\text { Marginal } \\
\text { impact }\end{array}$ & Estimate & $z$-statistic & $\begin{array}{l}\text { Marginal } \\
\text { impact }\end{array}$ \\
\hline$\phi$ & $30,430.033$ & 8.8881 & & 5667.8556 & 8.8887 & \\
\hline$\theta_{0}($ Intercept $)$ & -2.549 & -70.1824 & -0.1738 & -1.6938 & -30.9319 & -0.322 \\
\hline$\theta_{1}($ EconAct $)$ & 0.0005 & 2.4619 & 0 & 0.0001 & 0.3237 & 0 \\
\hline$\theta_{2}$ (Imports) & -0.0002 & -6.41 & 0 & 0.0001 & 1.0381 & 0 \\
\hline$\theta_{3}(\mathrm{M} 1)$ & 0 & -1.6455 & 0 & 0.0001 & 4.3691 & 0 \\
\hline$\theta_{4}($ Return on Oil $)$ & 0.0062 & 0.2515 & 0.0004 & -0.0103 & -0.2802 & -0.002 \\
\hline$\theta_{5}($ VolCorn $)$ & -0.9513 & -1.0251 & -0.0649 & -0.2598 & -0.1873 & -0.0494 \\
\hline$\theta_{6}($ VolSoy $)$ & -1.1632 & -0.9433 & -0.0793 & 4.208 & 2.3415 & 0.8 \\
\hline$\theta_{7}$ (VolRice) & -4.3038 & -4.8952 & -0.2935 & -1.2858 & -0.9834 & -0.2444 \\
\hline$\theta_{8}($ VolWCBOT $)$ & 7.5635 & 2.5548 & 0.5157 & 4.292 & 0.9573 & 0.8159 \\
\hline$\theta_{9}($ VolWKCBT $)$ & -2.8503 & -1.2763 & -0.1944 & -2.7598 & -0.8161 & -0.5247 \\
\hline Pseudo- $R^{2}$ & 0.88 & & & & 0.81 & \\
\hline
\end{tabular}

Table 11.9 Model: $Y_{t I_{F}}-$ Guatemala, $n=87$

\begin{tabular}{|c|c|c|c|c|c|c|}
\hline \multirow[b]{2}{*}{ Parameter } & \multicolumn{3}{|c|}{ Breads and cereals } & \multicolumn{3}{|l|}{ Meat } \\
\hline & Estimate & $z$-statistic & $\begin{array}{l}\text { Marginal } \\
\text { impact }\end{array}$ & Estimate & $z$-statistic & $\begin{array}{l}\text { Marginal } \\
\text { impact }\end{array}$ \\
\hline$\phi$ & 4298.7881 & 6.5953 & & $146,788.96$ & 6.5954 & \\
\hline$\theta_{0}($ Intercept $)$ & -2.9855 & -24.5471 & -0.3232 & -2.4889 & -96.4172 & -0.1709 \\
\hline$\theta_{1}($ EconAct $)$ & -0.0008 & -0.6875 & -0.0001 & 0.0001 & 0.6322 & 0 \\
\hline$\theta_{2}$ (Imports) & 0.0002 & 1.7144 & 0 & 0 & -1.1404 & 0 \\
\hline$\theta_{3}(\mathrm{M} 1)$ & 0.0002 & 11.7713 & 0 & 0 & -6.0762 & 0 \\
\hline$\theta_{4}($ Return on Oil) & 0.0757 & 0.9064 & 0.0082 & -0.0175 & -1.0212 & -0.0012 \\
\hline$\theta_{5}($ VolCorn $)$ & -11.8679 & -3.44 & -1.2849 & 1.8097 & 2.6906 & 0.1242 \\
\hline$\theta_{6}($ VolSoy $)$ & 22.4028 & 7.5817 & 2.4255 & -0.9991 & -1.605 & -0.0686 \\
\hline$\theta_{7}$ (VolRice) & 8.2857 & 2.5947 & 0.8971 & -1.567 & -2.5122 & -0.1076 \\
\hline$\theta_{8}($ VolWCBOT $)$ & -18.6606 & -1.9522 & -2.0204 & 1.1373 & 0.5625 & 0.0781 \\
\hline$\theta_{9}($ VolWKCBT $)$ & 5.419 & 0.5968 & 0.5867 & -2.4823 & -1.3201 & -0.1704 \\
\hline Pseudo- $R^{2}$ & 0.98 & & & & 0.93 & \\
\hline
\end{tabular}


Table 11.10 Model: $Y_{t I_{F}}$-Guatemala, $n=87$

\begin{tabular}{l|l|r|l|l|r|l}
\hline & \multicolumn{2}{|l|}{ Milk and other dairy products } & \multicolumn{2}{l}{ Other foods } \\
\cline { 2 - 8 } Parameter & Estimate & $z$-statistic & $\begin{array}{l}\text { Marginal } \\
\text { impact }\end{array}$ & Estimate & $z$-statistic & $\begin{array}{l}\text { Marginal } \\
\text { impact }\end{array}$ \\
\hline$\phi$ & $65,680.907$ & 6.5953 & & $25,657.83$ & 6.5955 & \\
\hline$\theta_{0}$ (Intercept $)$ & -3.3321 & -64.5307 & -0.1212 & -1.4485 & -36.6358 & -0.2782 \\
\hline$\theta_{1}($ EconAct $)$ & 0.0002 & 0.3783 & 0 & 0.0009 & 2.5545 & 0.0002 \\
\hline$\theta_{2}($ Imports $)$ & 0 & -0.7157 & 0 & 0 & -1.1066 & 0 \\
\hline$\theta_{3}($ M1 $)$ & 0 & -1.4175 & 0 & 0 & -2.6884 & 0 \\
\hline$\theta_{4}($ Return on Oil $)$ & -0.0183 & -0.5276 & -0.0007 & 0.0335 & 1.2704 & 0.0064 \\
\hline$\theta_{5}($ VolCorn $)$ & 0.0587 & 0.043 & 0.0021 & 1.775 & 1.7126 & 0.3409 \\
\hline$\theta_{6}($ VolSoy $)$ & -1.6323 & -1.2926 & -0.0594 & -4.0444 & -4.2128 & -0.7768 \\
\hline$\theta_{7}($ VolRice $)$ & -3.3057 & -2.6103 & -0.1202 & 0.9904 & 1.0305 & 0.1902 \\
\hline$\theta_{8}($ VolWCBOT $)$ & 8.1127 & 2.0038 & 0.295 & 3.9504 & 1.2751 & 0.7588 \\
\hline$\theta_{9}($ VolWKCBT $)$ & 2.8203 & 0.7445 & 0.1025 & -4.0736 & -1.4118 & -0.7825 \\
\hline Pseudo- $R^{2}$ & 0.58 & & & & 0.73 & \\
\hline & & & & & & \\
\hline
\end{tabular}

Table 11.11 Model: $Y_{t I_{F}}-$ Honduras, $n=96$

\begin{tabular}{|c|c|c|c|c|c|c|}
\hline \multirow[b]{2}{*}{ Parameter } & \multicolumn{3}{|c|}{ Breads and cereals } & \multicolumn{3}{|l|}{ Meat } \\
\hline & Estimate & $z$-statistic & $\begin{array}{l}\text { Marginal } \\
\text { impact }\end{array}$ & Estimate & $z$-statistic & $\begin{array}{l}\text { Marginal } \\
\text { impact }\end{array}$ \\
\hline$\phi$ & $14,598.789$ & 6.9279 & & $48,382.299$ & 6.9281 & \\
\hline$\theta_{0}($ Intercept $)$ & -2.585 & -26.1313 & -0.1452 & -2.3455 & -43.8583 & -0.1391 \\
\hline$\theta_{1}($ EconAct $)$ & -0.0053 & -7.3732 & -0.0003 & -0.0017 & -4.43 & -0.0001 \\
\hline$\theta_{2}$ (Imports) & 0.0005 & 4.8968 & 0 & 0.0001 & 2.1388 & 0 \\
\hline$\theta_{3}(\mathrm{M} 1)$ & 0.0001 & 0.8068 & 0 & 0 & -1.0715 & 0 \\
\hline$\theta_{4}($ Return on Oil $)$ & -0.0571 & -1.0855 & -0.0032 & -0.0273 & -0.9683 & -0.0016 \\
\hline$\theta_{5}($ VolCorn $)$ & -1.0199 & -0.4448 & -0.0573 & 3.9446 & 3.212 & 0.234 \\
\hline$\theta_{6}($ VolSoy $)$ & -2.084 & -0.8758 & -0.117 & -8.0223 & -6.2669 & -0.4759 \\
\hline$\theta_{7}$ (VolRice) & -2.5027 & -1.2808 & -0.1406 & -1.8207 & -1.7399 & -0.108 \\
\hline$\theta_{8}($ VolWCBOT $)$ & 7.9671 & 0.9622 & 0.4474 & -3.7906 & -0.8517 & -0.2249 \\
\hline$\theta_{9}($ VolWKCBT $)$ & 10.1606 & 1.6438 & 0.5706 & -4.2284 & -1.2683 & -0.2508 \\
\hline Pseudo- $R^{2}$ & 0.75 & & & & 0.90 & \\
\hline
\end{tabular}


Table 11.12 Model: $Y_{t I_{F}}$ - Honduras, $n=96$

\begin{tabular}{|c|c|c|c|c|c|c|}
\hline \multirow[b]{2}{*}{ Parameter } & \multicolumn{3}{|c|}{ Milk and other dairy products } & \multicolumn{3}{|l|}{ Other foods } \\
\hline & Estimate & z-statistic & $\begin{array}{l}\text { Marginal } \\
\text { impact }\end{array}$ & Estimate & z-statistic & $\begin{array}{l}\text { Marginal } \\
\text { impact }\end{array}$ \\
\hline$\phi$ & $34,209.087$ & 6.928 & & $13,181.435$ & 6.9283 & \\
\hline$\theta_{0}($ Intercept $)$ & -2.6426 & -37.6436 & -0.1261 & -1.3638 & -20.9949 & -0.2263 \\
\hline$\theta_{1}($ EconAct $)$ & -0.0037 & -7.2297 & -0.0002 & -0.0032 & -6.957 & -0.0005 \\
\hline$\theta_{2}$ (Imports) & 0.0003 & 4.0397 & 0 & 0.0003 & 4.3367 & 0.0001 \\
\hline$\theta_{3}(\mathrm{M} 1)$ & 0.0002 & 3.8116 & 0 & 0.0001 & 2.3503 & 0 \\
\hline$\theta_{4}($ Return on Oil $)$ & -0.0496 & -1.334 & -0.0024 & -0.0525 & -1.5292 & -0.0087 \\
\hline$\theta_{5}($ VolCorn $)$ & -1.5597 & -0.9562 & -0.0744 & 1.3954 & 0.9295 & 0.2315 \\
\hline$\theta_{6}$ (VolSoy) & -4.8124 & -2.8469 & -0.2297 & -1.6185 & -1.048 & -0.2685 \\
\hline$\theta_{7}($ VolRice $)$ & -1.5132 & -1.0887 & -0.0722 & -2.8316 & -2.2052 & -0.4698 \\
\hline$\theta_{8}($ VolWCBOT $)$ & -7.0353 & -1.1958 & -0.3358 & 0.4223 & 0.0777 & 0.0701 \\
\hline$\theta_{9}($ VolWKCBT $)$ & 4.877 & 1.1178 & 0.2328 & 0.2002 & 0.0496 & 0.0332 \\
\hline Pseudo- $R^{2}$ & 0.77 & & & & 0.71 & \\
\hline
\end{tabular}

Table 11.13 Model: $Y_{t I_{F}}-$ Mexico, $n=159$

\begin{tabular}{|c|c|c|c|c|c|c|}
\hline \multirow[b]{2}{*}{ Parameter } & \multicolumn{3}{|c|}{ Breads and cereals } & \multicolumn{3}{|l|}{ Meat } \\
\hline & Estimate & $z$-statistic & $\begin{array}{l}\text { Marginal } \\
\text { impact }\end{array}$ & Estimate & $z$-statistic & $\begin{array}{l}\text { Marginal } \\
\text { impact }\end{array}$ \\
\hline$\phi$ & $18,585.355$ & 8.9154 & & 5369.5718 & 8.915 & \\
\hline$\theta_{0}$ (Intercept) & -3.5081 & -32.6184 & -0.1168 & -1.9976 & -13.1078 & -0.1125 \\
\hline$\theta_{1}($ EconAct $)$ & 0.0002 & 0.118 & 0 & -0.0071 & -3.3766 & -0.0004 \\
\hline$\theta_{2}$ (Imports) & 0 & 2.6326 & 0 & 0 & 3.5931 & 0 \\
\hline$\theta_{3}(\mathrm{M} 1)$ & 0 & -1.9315 & 0 & 0 & -5.1358 & 0 \\
\hline$\theta_{4}($ Return on Oil $)$ & 0.0704 & 1.5813 & 0.0023 & -0.0194 & -0.3014 & -0.0011 \\
\hline$\theta_{5}($ VolCorn $)$ & 1.8294 & 1.1281 & 0.0609 & 6.605 & 2.8381 & 0.3718 \\
\hline$\theta_{6}($ VolSoy $)$ & -2.6105 & -1.2018 & -0.0869 & -1.784 & -0.5532 & -0.1004 \\
\hline$\theta_{7}($ VolRice $)$ & -6.2146 & -3.7211 & -0.2069 & -17.8027 & -7.3128 & -1.0022 \\
\hline$\theta_{8}($ VolWCBOT $)$ & 9.193 & 1.8751 & 0.3061 & 0.2148 & 0.0305 & 0.0121 \\
\hline$\theta_{9}($ VolWKCBT $)$ & -1.1962 & -0.2925 & -0.0398 & -2.0003 & -0.3489 & -0.1126 \\
\hline Pseudo- $R^{2}$ & 0.63 & & & & 0.88 & \\
\hline
\end{tabular}


Table 11.14 Model: $Y_{t I_{F}}-$ Mexico, $n=159$

\begin{tabular}{l|l|r|l|l|r|l}
\hline & \multicolumn{2}{l}{ Milk and other dairy products } & \multicolumn{2}{l}{ Other foods } \\
\cline { 2 - 8 } Parameter & Estimate & $z$-statistic & $\begin{array}{l}\text { Marginal } \\
\text { impact }\end{array}$ & Estimate & $z$-statistic & $\begin{array}{l}\text { Marginal } \\
\text { impact }\end{array}$ \\
\hline$\phi$ & 8191.7135 & 8.9149 & & 8349.1367 & 8.9159 & \\
\hline$\theta_{0}($ Intercept $)$ & -2.5171 & -17.6153 & -0.1044 & -2.2455 & -20.5959 & -0.1644 \\
\hline$\theta_{1}($ EconAct $)$ & -0.0065 & -3.3301 & -0.0003 & -0.0024 & -1.6152 & -0.0002 \\
\hline$\theta_{2}$ Imports $)$ & 0 & 4.4809 & 0 & 0 & 3.3767 & 0 \\
\hline$\theta_{3}($ M1 $)$ & 0 & -6.0912 & 0 & 0 & -6.1153 & 0 \\
\hline$\theta_{4}($ Return on Oil $)$ & 0.0212 & 0.3538 & 0.0009 & -0.0103 & -0.2262 & -0.0008 \\
\hline$\theta_{5}($ VolCorn $)$ & 3.7388 & 1.7097 & 0.1551 & 2.3254 & 1.3982 & 0.1702 \\
\hline$\theta_{6}($ VolSoy $)$ & -7.3896 & -2.4292 & -0.3066 & -8.1107 & -3.5465 & -0.5936 \\
\hline$\theta_{7}($ VolRice $)$ & -14.9432 & -6.5592 & -0.62 & -7.112 & -4.1495 & -0.5205 \\
\hline$\theta_{8}($ VolWCBOT $)$ & 10.5947 & 1.6134 & 0.4396 & 6.3139 & 1.2587 & 0.4621 \\
\hline$\theta_{9}($ VolWKCBT $)$ & -0.6629 & -0.1234 & -0.0275 & -0.627 & -0.152 & -0.0459 \\
\hline Pseudo- $R^{2}$ & 0.86 & & & & 0.81 & \\
\hline
\end{tabular}

Table 11.15 Model: $Y_{t I_{F}}$-Nicaragua, $n=88$

\begin{tabular}{l|l|r|l|l|r|l}
\hline & \multicolumn{3}{l}{ Breads and cereals } & \multicolumn{2}{l}{ Meat } \\
\cline { 2 - 8 } Parameter & Estimate & $z$-statistic & $\begin{array}{l}\text { Marginal } \\
\text { impact }\end{array}$ & Estimate & $z$-statistic & $\begin{array}{l}\text { Marginal } \\
\text { impact }\end{array}$ \\
\hline$\phi$ & $23,124.049$ & 6.6331 & & $28,388.756$ & 6.6331 & \\
\hline$\theta_{0}$ (Intercept) & -2.9785 & -61.2473 & -0.2098 & -2.557 & -55.4856 & -0.18 \\
\hline$\theta_{1}($ EconAct $)$ & 0.0002 & 0.8483 & 0 & 0.0001 & 0.3479 & 0 \\
\hline$\theta_{2}($ Imports $)$ & 0.0004 & 4.291 & 0 & 0.0001 & 1.7132 & 0 \\
\hline$\theta_{3}($ M1 $)$ & 0.0005 & 5.2454 & 0 & 0 & 0.3868 & 0 \\
\hline$\theta_{4}($ Return on Oil $)$ & 0.0511 & 1.2112 & 0.0036 & -0.03 & -0.7928 & -0.0021 \\
\hline$\theta_{5}($ VolCorn $)$ & -1.4927 & -0.8725 & -0.1052 & 2.3858 & 1.5672 & 0.1679 \\
\hline$\theta_{6}($ VolSoy $)$ & 7.6796 & 5.1633 & 0.541 & -3.8797 & -2.8563 & -0.2731 \\
\hline$\theta_{7}($ VolRice $)$ & -2.4418 & -1.6053 & -0.172 & 3.5647 & 2.6457 & 0.2509 \\
\hline$\theta_{8}($ VolWCBOT $)$ & 1.3202 & 0.2667 & 0.093 & -2.5505 & -0.5616 & -0.1795 \\
\hline$\theta_{9}($ VolWKCBT $)$ & 4.8302 & 1.0473 & 0.3403 & -4.9979 & -1.2009 & -0.3518 \\
\hline Pseudo- $R^{2}$ & 0.94 & & & & 0.88 & \\
\hline
\end{tabular}


Table 11.16 Model: $Y_{t I_{F}}-$ Nicaragua, $n=88$

\begin{tabular}{|c|c|c|c|c|c|c|}
\hline \multirow[b]{2}{*}{ Parameter } & \multicolumn{3}{|c|}{ Milk and other dairy products } & \multicolumn{3}{|l|}{ Other foods } \\
\hline & Estimate & $z$-statistic & $\begin{array}{l}\text { Marginal } \\
\text { impact }\end{array}$ & Estimate & $z$-statistic & $\begin{array}{l}\text { Marginal } \\
\text { impact }\end{array}$ \\
\hline$\phi$ & 8894.0985 & 6.6327 & & $12,171.234$ & 6.6334 & \\
\hline$\theta_{0}($ Intercept $)$ & -2.8914 & -32.9862 & -0.168 & -1.6241 & -36.4102 & -0.3154 \\
\hline$\theta_{1}($ EconAct $)$ & -0.0002 & -0.6858 & 0 & 0.0002 & 0.9527 & 0 \\
\hline$\theta_{2}$ (Imports) & -0.0005 & -2.9821 & 0 & 0.0003 & 3.8202 & 0.0001 \\
\hline$\theta_{3}(\mathrm{M} 1)$ & 0.0007 & 4.0906 & 0 & 0.0003 & 4.1596 & 0.0001 \\
\hline$\theta_{4}($ Return on Oil $)$ & 0.1163 & 1.5761 & 0.0068 & 0.0444 & 1.1844 & 0.0086 \\
\hline$\theta_{5}($ VolCorn $)$ & -10.1085 & -3.3629 & -0.5872 & 2.7707 & 1.8333 & 0.538 \\
\hline$\theta_{6}$ (VolSoy) & -4.7079 & -1.7503 & -0.2735 & 0.3458 & 0.2589 & 0.0672 \\
\hline$\theta_{7}($ VolRice $)$ & -3.62 & -1.3816 & -0.2103 & 0.1308 & 0.0975 & 0.0254 \\
\hline$\theta_{8}($ VolWCBOT $)$ & 17.1722 & 1.9661 & 0.9976 & -4.24 & -0.9516 & -0.8234 \\
\hline$\theta_{9}($ VolWKCBT $)$ & 3.447 & 0.4277 & 0.2002 & 1.7843 & 0.4344 & 0.3465 \\
\hline Pseudo- $R^{2}$ & 0.88 & & & & 0.81 & \\
\hline
\end{tabular}

Table 11.17 Model: $Y_{t I_{F}}-$ Panama, $n=79$

\begin{tabular}{|c|c|c|c|c|c|c|}
\hline \multirow[b]{2}{*}{ Parameter } & \multicolumn{3}{|c|}{ Breads and cereals } & \multicolumn{3}{|l|}{ Meat } \\
\hline & Estimate & $z$-statistic & $\begin{array}{l}\text { Marginal } \\
\text { impact }\end{array}$ & Estimate & $z$-statistic & $\begin{array}{l}\text { Marginal } \\
\text { impact }\end{array}$ \\
\hline$\phi$ & $42,836.899$ & 6.2847 & & $27,901.146$ & 6.2848 & \\
\hline$\theta_{0}($ Intercept $)$ & -3.3296 & -48.3513 & -0.1477 & -2.5388 & -39.1479 & -0.2065 \\
\hline$\theta_{1}($ EconAct $)$ & -0.0012 & -2.3271 & -0.0001 & 0.0008 & 1.6198 & 0.0001 \\
\hline$\theta_{2}$ (Imports) & 0.0001 & 3.0469 & 0 & 0 & -0.6296 & 0 \\
\hline$\theta_{3}(\mathrm{M} 1)$ & 0.0001 & 6.2054 & 0 & 0 & 1.0226 & 0 \\
\hline$\theta_{4}($ Return on Oil $)$ & 0.0334 & 1.1603 & 0.0015 & 0.0145 & 0.5335 & 0.0012 \\
\hline$\theta_{5}($ VolCorn $)$ & -4.9734 & -2.2377 & -0.2207 & 3.0768 & 1.4729 & 0.2502 \\
\hline$\theta_{6}($ VolSoy $)$ & 3.9587 & 2.7148 & 0.1757 & -0.2289 & -0.1686 & -0.0186 \\
\hline$\theta_{7}($ VolRice $)$ & 0.2367 & 0.1261 & 0.0105 & 1.5116 & 0.8705 & 0.1229 \\
\hline$\theta_{8}($ VolWCBOT $)$ & 13.9842 & 3.0451 & 0.6205 & -4.0673 & -0.9367 & -0.3308 \\
\hline$\theta_{9}($ VolWKCBT $)$ & -1.0518 & -0.2336 & -0.0467 & -1.3298 & -0.3149 & -0.1081 \\
\hline Pseudo- $R^{2}$ & 0.95 & & & & 0.70 & \\
\hline
\end{tabular}


Table 11.18 Model: $Y_{t I_{F}}-$ Panama, $n=79$

\begin{tabular}{|c|c|c|c|c|c|c|}
\hline \multirow[b]{2}{*}{ Parameter } & \multicolumn{3}{|c|}{ Milk and other dairy products } & \multicolumn{3}{|l|}{ Other foods } \\
\hline & Estimate & $z$-statistic & $\begin{array}{l}\text { Marginal } \\
\text { impact }\end{array}$ & Estimate & $z$-statistic & $\begin{array}{l}\text { Marginal } \\
\text { impact }\end{array}$ \\
\hline$\phi$ & $30,599.764$ & 6.2845 & & $19,812.572$ & 6.285 & \\
\hline$\theta_{0}($ Intercept $)$ & -3.9488 & -41.1289 & -0.1244 & -2.0358 & -34.6196 & -0.3042 \\
\hline$\theta_{1}($ EconAct $)$ & 0.001 & 1.4929 & 0 & 0.0006 & 1.5135 & 0.0001 \\
\hline$\theta_{2}$ (Imports) & 0 & 0.2854 & 0 & -0.0001 & -3.8037 & 0 \\
\hline$\theta_{3}(\mathrm{M} 1)$ & 0.0001 & 3.3279 & 0 & 0 & 4.291 & 0 \\
\hline$\theta_{4}($ Return on Oil $)$ & -0.0364 & -0.9104 & -0.0011 & -0.037 & -1.5032 & -0.0055 \\
\hline$\theta_{5}($ VolCorn $)$ & -12.6476 & -4.0779 & -0.3984 & -1.4221 & -0.7495 & -0.2125 \\
\hline$\theta_{6}$ (VolSoy) & 8.5396 & 4.2007 & 0.269 & 4.6104 & 3.7345 & 0.6888 \\
\hline$\theta_{7}($ VolRice $)$ & 1.7534 & 0.6661 & 0.0552 & 0.7373 & 0.4654 & 0.1102 \\
\hline$\theta_{8}($ VolWCBOT $)$ & -0.5952 & -0.0932 & -0.0187 & 2.2778 & 0.5795 & 0.3403 \\
\hline$\theta_{9}($ VolWKCBT $)$ & 16.9397 & 2.705 & 0.5336 & 3.5562 & 0.9275 & 0.5313 \\
\hline Pseudo- $R^{2}$ & 0.94 & & & & 0.92 & \\
\hline
\end{tabular}

Table 11.19 Model: $Y_{t I_{F}}$-Peru, $n=152$

\begin{tabular}{|c|c|c|c|c|c|c|}
\hline \multirow[b]{2}{*}{ Parameter } & \multicolumn{3}{|c|}{ Breads and cereals } & \multicolumn{3}{|l|}{ Meat } \\
\hline & Estimate & $z$-statistic & $\begin{array}{l}\text { Marginal } \\
\text { impact }\end{array}$ & Estimate & $z$-statistic & $\begin{array}{l}\text { Marginal } \\
\text { impact }\end{array}$ \\
\hline$\phi$ & $10,649.305$ & 8.7177 & & 5867.4867 & 8.7175 & \\
\hline$\theta_{0}($ Intercept $)$ & -2.2777 & -51.2681 & -0.2132 & -1.7373 & -28.2889 & -0.1568 \\
\hline$\theta_{1}($ EconAct $)$ & -0.0007 & -2.2116 & -0.0001 & -0.0031 & -6.8838 & -0.0003 \\
\hline$\theta_{2}$ (Imports) & 0.0001 & 6.9847 & 0 & 0.0003 & 10.029 & 0 \\
\hline$\theta_{3}(\mathrm{M} 1)$ & 0 & -1.39 & 0 & 0 & -6.4168 & 0 \\
\hline$\theta_{4}($ Return on Oil $)$ & 0.0446 & 1.2385 & 0.0042 & 0.0391 & 0.7958 & 0.0035 \\
\hline$\theta_{5}($ VolCorn $)$ & -2.4112 & -1.8183 & -0.2257 & 2.2836 & 1.2644 & 0.2061 \\
\hline$\theta_{6}($ VolSoy $)$ & 8.627 & 4.9168 & 0.8076 & -7.3505 & -2.9558 & -0.6634 \\
\hline$\theta_{7}($ VolRice $)$ & -5.3316 & -3.9281 & -0.4991 & -12.0382 & -6.4187 & -1.0865 \\
\hline$\theta_{8}($ VolWCBOT $)$ & -6.1178 & -1.5146 & -0.5727 & -5.9913 & -1.0871 & -0.5407 \\
\hline$\theta_{9}($ VolWKCBT $)$ & 7.8244 & 2.268 & 0.7325 & 10.5296 & 2.2921 & 0.9503 \\
\hline Pseudo- $R^{2}$ & 0.81 & & & & 0.87 & \\
\hline
\end{tabular}


Table 11.20 Model: $Y_{t I_{F}}-$ Peru, $n=152$

\begin{tabular}{l|l|c|l|l|r|l}
\hline & \multicolumn{3}{|l|}{ Milk and other dairy products } & \multicolumn{2}{l}{ Other foods } \\
\cline { 2 - 8 } Parameter & Estimate & $z$-statistic & $\begin{array}{l}\text { Marginal } \\
\text { impact }\end{array}$ & Estimate & $z$-statistic & $\begin{array}{l}\text { Marginal } \\
\text { impact }\end{array}$ \\
\hline$\phi$ & $25,927.176$ & 8.7173 & & 4281.78 & 8.7186 & \\
\hline$\theta_{0}$ (Intercept $)$ & -2.9624 & -69.5966 & -0.1187 & -0.7408 & -15.7126 & -0.1931 \\
\hline$\theta_{1}($ EconAct $)$ & -0.002 & -6.502 & -0.0001 & -0.0017 & -4.9396 & -0.0004 \\
\hline$\theta_{2}$ Imports $)$ & 0.0001 & 6.299 & 0 & 0.0001 & 3.3777 & 0 \\
\hline$\theta_{3}$ (M1) & 0 & -3.1206 & 0 & 0 & 0.4413 & 0 \\
\hline$\theta_{4}($ Return on Oil $)$ & 0.0555 & 1.622 & 0.0022 & 0.0059 & 0.157 & 0.0015 \\
\hline$\theta_{5}($ VolCorn $)$ & 2.0215 & 1.6189 & 0.081 & 3.1737 & 2.3028 & 0.827 \\
\hline$\theta_{6}($ VolSoy $)$ & -1.4678 & -0.8619 & -0.0588 & -3.3824 & -1.8061 & -0.8814 \\
\hline$\theta_{7}($ VolRice $)$ & -5.5173 & -4.266 & -0.2211 & -7.4991 & -5.2855 & -1.9542 \\
\hline$\theta_{8}($ VolWCBOT $)$ & -1.7307 & -0.4505 & -0.0694 & -1.0336 & -0.2425 & -0.2693 \\
\hline$\theta_{9}($ VolWKCBT $)$ & 8.6824 & 2.6816 & 0.348 & -0.681 & -0.1887 & -0.1775 \\
\hline Pseudo- $R^{2}$ & 0.77 & & & & 0.70 & \\
\hline & & & & & &
\end{tabular}

\section{Data Sources}

For oil prices the source is always U.S. Energy Information Administration (EIA), and for the volatility of international commodities the source is the estimation procedure described in the text.

- Costa Rica-Share of Laspeyres index: Instituto Nacional de Estadistica y Censos de Costa Rica (INEC); Monthly Index of economic activity: Banco Central de Costa Rica; Imports: Banco Central de Costa Rica.

- El Salvador-Share of Laspeyres index: Direccion General de Estadística y Censos (DIGESTYC); Monthly Index of economic activity: Banco Central de Reserva de El Salvador; Imports: Banco Central de Reserva de El Salvador.

- Guatemala-Share of Laspeyres index: Instituto Nacional de Estadistica Guatemala (INE); Monthly Index of economic activity: Banco de Guatemala; Imports: Banco de Guatemala.

- Honduras - Share of Laspeyres index: Instituto Nacional de Estadistica, Honduras (INE); Monthly Index of economic activity: Banco Central de Honduras; Imports: Banco Central de Honduras.

- Ecuador-Share of Laspeyres index: Instituto Nacional de Estadística de Ecuador (INEC); Monthly Index of economic activity: Banco Central del Ecuador; Imports: Banco Central del Ecuador.

- Peru-Share of Laspeyres index: Instituto Nacional de Estadistica e Informatica (INEI); Monthly Index of economic activity: Banco Central de Reserva del Peru; Imports: Banco Central de Reserva del Peru. 
- Mexico-Share of Laspeyres index: Instituto Nacional de Estadistica y Geografia (INEGI); Monthly Index of economic activity: Banco de Mexico; Imports: Banco de Mexico.

- Nicaragua-Share of Laspeyres index: Instituto Nacional de Informacion de Desarrollo (INIDE); Monthly Index of economic activity: Banco Central de Nicaragua; Imports: Banco Central de Nicaragua.

- Panama-Share of Laspeyres index: Contraloria General de la Republica; Monthly Index of economic activity: Contraloria General de la Republica; Imports: Contraloria General de la Republica.

- Dominican Republic-Share of Laspeyres index: Oficina Nacional de Estadistica (ONE); Monthly Index of economic activity: missing; Imports: Banco Central de la Republica Dominicana.

Open Access This chapter is distributed under the terms of the Creative Commons AttributionNoncommercial 2.5 License (http://creativecommons.org/licenses/by-nc/2.5/) which permits any noncommercial use, distribution, and reproduction in any medium, provided the original author(s) and source are credited.

The images or other third party material in this chapter are included in the work's Creative Commons license, unless indicated otherwise in the credit line; if such material is not included in the work's Creative Commons license and the respective action is not permitted by statutory regulation, users will need to obtain permission from the license holder to duplicate, adapt or reproduce the material.

\section{References}

Anderson K, Nelgen S (2012) Agricultural trade distortions during the global financial crisis. Oxf Rev Econ Policy 28:1-26

Bollerslev T (1986) Generalized autoregressive conditional heteroskedasticity. J Econometr 31:307-327

Ceballos F, Hernandez M, Minot N, Robles M (2015) Transmission of food price volatility from international to domestic markets: evidence from Africa, Latin America and South Asia. Working paper, International Food Policy Research Institute

Deaton A (1989) Rice prices and income distribution in thailand: a nonparametric analysis. Econ J 99:1-37

de Hoyos R, Medved D (2011) Poverty effects of higher food prices: a global perspective. Rev Dev Econ 15:387-402

Engle RF (1982) Autoregressive conditional heteroscedasticity with estimates of the variance of United Kingdom inflation. Econometrica 50:987-1008

Fan J, Yao Q (1998) Efficient estimation of conditional variance functions in stochastic regression. Biometrika 85:645-660

Ferrari S, Cribari-Neto F (2004) Beta regression for modeling rates and proportions. J Appl Stat 31:799-815

Hernandez M, Ibarra R, Trupkin D (2014) How far do shocks move across borders? Examining volatility transmission in major agricultural futures markets. Eur Rev Agric Econ 41:301-325

Ivanic M, Martin W (2008) Implications of higher global food prices for poverty in low-income countries. Agric Econ 39:405-416

Ivanic M, Martin W, Zaman H (2012) Estimating the short-run poverty impacts of the 2010 surge in food prices. World Dev 40:2302-2317 
Jacoby H (2013) Food prices, wages and welfare in rural India. In: Policy research working paper, 6412. World Bank, Washington, DC

Kim W, Linton OB, Hengartner N (1999) A computationally efficient oracle estimator for additive nonparametric regression with bootstrap confidence intervals. J Comput Graph Stat 8:278-297

Martin W, Anderson K (2011) Export restrictions and price insulation during commodity price booms. In: Policy research working paper, 5645. World Bank, Washington, DC

Martins-Filho C, Yao F, Torero M (2013) Nonparametric estimation of conditional value-atrisk and expected shortfall based on extreme value theory. University of Colorado, Boulder. Available at http://spot.colorado.edu/ martinsc/Research.html

Martins-Filho C, Yao F, Torero M (2015) High order conditional quantile estimation based on nonparametric models of regression. Econometr Rev 34:906-957

Marquardt D (1963) An algorithm for least-squares estimation of nonlinear parameters. SIAM J Appl Math 11:431-441

Minot N (2014) Food price volatility in sub-Saharan Africa: has it really increased? Food Policy 45:45-56

Newey W, McFadden D (1994) Large sample estimation and hypothesis testing. In: Engle RF, McFadden DL (eds) Handbook of econometrics, vol 4. Elsevier, Amsterdam, pp 2111-2245

Torero M (2012) Food prices: riding the rollercoaster. In: 2011 global food policy report. International Food Policy Research Institute, Washington, DC

Wodon Q, Zaman H (2010) Higher food prices in sub-saharan Africa: poverty impact and policy responses. World Bank Res Obs 25:157-176

World Bank (2010) Food price increases in South Asia: national responses and regional dimensions. Technical report, The World Bank - South Asia Region

Zhao J, Goodwin B (2011) Volatility spillovers in agricultural commodity markets: an application involving implied volatilities from option markets, working paper 